\title{
Experimental study on severe slugging mitigation applying wavy pipes
}

\author{
Lanchang Xing ${ }^{\text {a }}$, Hoi Yeung ${ }^{\text {a }}$, Joseph Shen ${ }^{\text {b }}$, Yi Cao ${ }^{\text {a }}$ \\ ${ }^{a}$ Process Systems Engineering Group, School of Engineering, Cranfield University, \\ Bedfordshire, MK43 0AL, United Kingdom \\ ${ }^{\mathrm{b}}$ Chevron Energy Technology Company, Houston, TX77002, United States
}

\begin{abstract}
Wavy pipes were installed in the pipeline for mitigating severe slugging in pipeline/riser systems. Experimental results have revealed that: with a wavy pipe applied, the operating region of severe slugging is reduced; the severity of severe slugging and oscillation flow is mitigated; the wavy pipe performs better with its outlet located upstream of the riser base. The wavy pipe is essentially reducing the slug length. For severe slugging the wavy pipe works by accelerating the movement of the gas in the pipeline to the riser base; for the oscillation flow it works by mixing the gas/liquid two phases.
\end{abstract}

Keywords: Severe slugging; Wavy pipe; Severe slugging mitigation; Pipeline/riser system; Multiphase flow; Flow assurance

\section{Introduction}

The exploitation of offshore hydrocarbon reservoirs is of crucial economic importance. As more easily accessible fields are depleted there is an increasing requirement to develop reservoirs in deepwater offshore. The offshore production system normally consists of four parts, i.e. subsea system, flowline/pipeline/riser system, fixed/floating structures and topside processing facilities (Lee, 2009). The subsea system is used to gather productions from multiple wellheads and send the productions with a smaller number of flowlines. These unprocessed productions, usually taking the form of multiphase fluids, are sent to the topside processing facilities on the fixed or floating structure through the pipeline/riser system. By transporting multiphase fluids in a single flowline the capital expenditure can be reduced because there is no need to install separating facilities, multiple pipelines and receiving facilities for separate phases. However, a few potential problems may arise during the transportation of multiphase fluids of oil, gas and water in the pipeline. For example, hydrocarbon fluids and water can form hydrate and block the pipeline; the wax and asphaltene can deposit on the wall and may eventually block the pipeline; the corrosion may occur when the water cut is high enough; scales may form and deposit inside the pipeline and restrict the flow; the severe slugging may form and cause operational problems to the downstream processing facilities (Guo et al., 2005). The problems in association with multiphase fluid transportation pose great challenges to 'flow assurance'. 
The term 'Flow Assurance' is thought to be first used by Petrobras in the early 1990s as 'Garantia de Fluxo', literally translated as 'Guarantee of Flow' or 'Flow Assurance' (Su, 2003). It originally covered only the thermal hydraulic and production chemistry issues encountered in the oil and gas production. However, it has become synonymous with a wide range of issues. Different descriptions or definitions have been proposed by many researchers. But it is well recognised that flow assurance is successful operations that generate a reliable, manageable and profitable flow of fluids from the reservoir to the sales point (Brown, 2002; Bai and Bai, 2005; Guo et al., 2005). The main concerns of flow assurance are highlighted as follows (Bai and Bai, 2005; Watson et al., 2003): (1) system deliverability: pressure drop versus production, pipeline size and boosting; (2) thermal behaviour: temperature distribution, temperature changes due to start-up and shutdown, insulation option and heating requirements; (3) production chemistry: hydrates, waxes, asphaltenes, scaling, sand, corrosivity and rheology; (4) operability characteristics: star-up, shutdown, transient behaviour (e.g. slugging) etc; (5) system performance: mechanical integrity, equipment reliability, system availability etc.

This work deals with one of the flow assurance concerns, i.e. severe slugging problem in pipeline/riser systems. At the late stage of the production field life when the reservoir pressure is low and the production is reduced, severe slugging usually forms in the pipeline/riser system due to the low gas and liquid flowrates. Severe slugging is a cyclic process consisting of four stages (Schmidt et al., 1985; Taitel, 1986), i.e. liquid buildup, slug production, gas penetration and gas-blowdown/liquid-feedback. Severe slugging can result in various problems to the whole production system. The problems exhibit great challenges to the steady operation of the production, mechanical integrity of the structure and efficient management of the reservoir as explained below:

Steady operation: challenged by the cyclic behaviour with a gas blowdown stage of very high liquid and gas delivery and a liquid buildup stage of no or very low flowrate. The highly unsteady operation conditions can lead to failure to meet the production specifications. The high delivery of liquid and gas can cause problems in controlling the downstream separators and compressors, which may result in overflow and shutdown of the separators and unnecessary flaring of gas.

Mechanical integrity: challenged by the long liquid slug and fast moving slug tail. The mechanical loading, corrosion and erosion on pipe bends, joints or valves can be increased significantly.

Reservoir management: challenged by the high riser base pressure and pressure fluctuation. The high riser base pressure can cause high backpressure on the reservoir and reduce the production; the high pressure fluctuation can result in poor performance of the recoverable reservoir.

Various severe slugging mitigation or elimination methods have been proposed since the severe slugging induced problems were identified by Yocum (1973). The major techniques or methods can be grouped into two categories, i.e. active and passive slug mitigation, based on whether the 'external interference' is needed or not in the operation. The external interference is essential to the implementation of the active 
slug mitigation methods. The active methods mainly include three types: topside choking at the riser top, external gas-lifting and control-based methods. The riser top choking method needs operators to adjust the opening of the choking valve manually (Schmidt et al., 1985; Taitel, 1986); the external-gas lifting needs compressors to compress the external gas and separate pipelines to transport the compressed gas to the designed injection places (Jansen et al., 1996); the control-based methods need controllers to adjust an actuator such as a valve to deal with different flow and operating conditions (Havre and Dalsmo, 2002; Storkaas, 2005; Sivertsen et al., 2010). The passive slug mitigation methods usually take the form of design changes to the facility itself such as sizing of slug catcher, gas lifting by rerouting the gas in the pipeline to the riser (Sarica and Tengesdal, 2000) and flow regime modification by a flow conditioner in the pipeline (Almeida and Gonçalves, 1999; Makogan and Brook, 2007). The function of the passive methods can be achieved without any external interference. Compared with the active methods the passive methods are less flexible as they can hardly be adjusted once the designed system is commissioned. However, there are remarkable advantages of these methods. They do not need extra investment on operators, compressors, measurement instruments and actuators. Furthermore, they can work in collaboration with the active methods, easing the challenge of severe slugging induced problems to the active methods and saving external resources.

A flow conditioner for severe slugging mitigation refers to a pipe section installed in the pipeline of pipeline/riser systems. As proposed by Schmidt et al. (1985) one of the necessary conditions for severe slugging to occur is that the flow regime in the pipeline is stratified flow. If the flow conditioners can modify the stratified flow to others in the pipeline upstream of the riser base, severe slugging can be eliminated or mitigated. A novel flow conditioner, wavy pipe, has been employed to mitigate severe slugging passively. A wavy pipe is a pipe section constructed by connecting standard piping bends in series in one plane. The wavy pipe located in the pipeline is expected to be able to modify the way of interaction between gas and liquid and further affect the flow behaviour in the whole pipeline/riser system. The work presented in this paper is to demonstrate the performance and disclose the working principle of the wavy pipe on severe slugging mitigation based on the experimental observations.

\section{Experimental campaigns}

\subsection{Wavy pipes}

A wavy pipe is a pipe section constructed using standard piping bends. The minimum unit of a wavy pipe is a piping bend, which can be described by three geometrical parameters. As shown in Fig. 1 (a) the key geometrical parameters of a bend include the internal diameter of the tube $(d)$, the radius of the bend $(R)$ and the angle of the bend $(\alpha)$. Fig. 1 (b) shows the schematic of a wavy pipe composed of 7 bends $(\alpha=$ $90^{\circ}$ ) and 2 elbows at the two ends of the wavy pipe. The angle of the elbow $(\beta)$ is selected to allow the wavy pipe to match the pipelines upstream and downstream. Therefore the elbow angle, $\beta$, is $45^{\circ}$ in Fig. 1 (b).

Fig. 2 shows the photograph of a 4" wavy pipe of 7 bends installed in the pipeline. The 4" wavy pipes tested in the experiment were constructed using short-radius bends and elbows made from ABS. The geometrical parameters of the bends were: $d=0.101$ 
$\mathrm{m}, R=0.216 \mathrm{~m}$ and $\alpha=90^{\circ}$.

In order to visualise the flow development in the wavy pipe the 2" wavy pipes were made of clear PVC components. Unfortunately the 2 " bends made from clear PVC were not available. Alternatively the 2 " 'bend' was constructed by connecting one $90^{\circ}$ elbow and two straight pipe sections at the two ends of the elbow. Fig. 3 shows the parameters of a 2" 'bend' and a 2" wavy pipe of 7 'bends'. The geometrical parameters are: $d=52 \mathrm{~mm}, R=96 \mathrm{~mm}$ and $\alpha=90^{\circ}$.

\subsection{Test facility and test configurations}

The experiment was conducted on the Three-Phase (air, oil and water) Test Facility (as shown in Fig. 4) at Cranfield University. The test facility comprises four parts: the fluid supply and metering area, valve manifold area, test area and separation area. This facility is controlled by the DeltaV ${ }^{\circledR}$ plant management system, a Fieldbus based Supervisory, Control and Data Acquisition (SCADA) system, to ensure that the system is monitored, the desired operation conditions are achieved and the required data are recorded. The facility is capable of supplying a controlled and measured flowrate of air, oil and water from the fluid supply and metering area into the test area and finally into the separation area where the air, oil and water are separated.

A maximum air flowrate of $1410 \mathrm{~m}^{3} / \mathrm{h}$ at 7 barg can be supplied by the compressors. Then the air accumulates in a receiver (maintained at $7 \mathrm{barg}$ ) to reduce the pressure fluctuations from the compressor. The water is supplied from a $12.5 \mathrm{~m}^{3}$ capacity water tank and the oil is supplied from an oil tank of similar capacity. The water and oil are supplied by two identical multistage Grundfos CR90-5 pumps respectively. A maximum flowrate of $100 \mathrm{~m}^{3} / \mathrm{h}$ at 10 barg can be supplied by each of them. The startup, speed control and shutdown of the two pumps are operated remotely through the DeltaV ${ }^{\circledR}$.

There are two pipeline/riser systems (2" vertical riser and 4" catenary riser) in the test area. The two riser systems can be run alternatively by setting appropriate valves in the valve manifold area. The 4" pipeline/riser system consists of a $55 \mathrm{~m}$ long pipeline with $2^{\circ}$ downwardly inclined and a catenary-shaped riser with a vertical height of $10.5 \mathrm{~m}$. The 2" pipeline is $40 \mathrm{~m}$ long and the riser is $11 \mathrm{~m}$ high. Each of the risers discharges the fluids into a vertical two-phase separator $(1.2 \mathrm{~m}$ high and $0.5 \mathrm{~m}$ in diameter) where the fluids are separated into liquid and gas for metering individually. The outlet air flow is measured by a vortex flow meter and the liquid by a Coriolis meter. A Coriolis meter is installed at the near vertical section at the top of the riser. The meter gives an indication of the fluid mass flowrate and density at the riser exit.

The air and liquid return to the three-phase separator. The air, water and oil are gravitationally separated in the horizontal three-phase separator. The pressure, oil/water interface level and gas/liquid interface level are controlled by a pressure controller and two level controllers, respectively. The pressure in the three-phase separator is controlled through the gas outlet valve. After separation in the three-phase separator the air is exhausted into atmosphere and the water and oil enter their respective coalescers, where the liquids are cleaned before returning to their respective storage tanks. 
The experiments were carried out on the 2" and 4" pipeline/riser systems with air and water as test fluids. The superficial liquid velocity $\left(U_{\mathrm{SL}}\right)$ ranges from $0.1 \mathrm{~m} / \mathrm{s}$ to 1.0 $\mathrm{m} / \mathrm{s}$ and superficial air velocity $\left(U_{\mathrm{SG} 0}\right)$ at standard conditions $\left(101325 \mathrm{~Pa}, 20{ }^{\circ} \mathrm{C}\right)$ is from $0.3 \mathrm{~m} / \mathrm{s}$ to $3.0 \mathrm{~m} / \mathrm{s}$. The pressure in the three-phase separator was controlled as 1 barg in each test run. It needs to be mentioned that the superficial air velocity at the standard conditions $\left(U_{\mathrm{SG} 0}\right)$ rather than at the local conditions of the pipeline/riser system have been used throughout this paper. Because $U_{\mathrm{SG} 0}$ is not affected by the fluctuating pressure and is consistent with the constant mass flowrate at the inlet of the pipeline/riser system.

The test configurations of the pipeline/wavy-pipe/riser systems are as follows:

Configuration I (CI): the outlet of the wavy pipe located at the riser base (2" and 4" wavy pipes of 7 bends); the $\mathrm{CI}$ is used to test the performance of the wavy pipes of different diameters.

Configuration II (CII): the outlet of the wavy pipe located at a distance from the riser base ( $1.5 \mathrm{~m}$ and $3 \mathrm{~m}$ for the 2" and 4" 7-bend wavy pipes, respectively); the CII is used to test the effects of the location of the wavy pipe in the pipeline on its performance.

Configuration III (CIII): the outlet of the wavy pipe located at the riser base (2" wavy pipe of 7 and 11 bends); the CIII is used to test the effects of the length of the wavy pipe on its performance.

Configuration IV (CIV): the outlet of the wavy pipe located at a distance $(1.5 \mathrm{~m})$ from the riser base (2" wavy pipe of 7 and 11 bends); the CIV is used to test the effects of both the location and length of the wavy pipe on its performance and compare with the results from the CIII.

\section{Characterisation of the flow in pipeline/riser systems}

\subsection{Flow regimes}

The flow regimes in a pipeline/riser system have been classified into different categories by different researchers (Linga, 1987; Schmidt et al., 1980; Taitel et al., 1990; Tin, 1991). In this work the flow regimes observed in the vertical and catenaryshaped riser in the experiment are classified into four categories, i.e. severe slugging (SS), transitional severe slugging (TSS), oscillation flow (OSC) and continuous flow $(\mathrm{CON})$. The flow regimes can be identified based on both visual observations and analysis of the differential pressure across the riser (riser DP). The flow regimes discussed in this paper are described below and typical riser DP time traces of the four flow regimes in the 2" pipeline/riser and pipeline/wavy-pipe/riser systems are shown in Fig. 5.

Severe Slugging (SS): There are four stages in one SS cycle: liquid buildup stage, slug production stage, bubble penetration stage and gas-blowdown/liquid-fallback stage. At the liquid buildup stage the slug length increases in both of the riser and pipeline and the riser DP increases gradually. Once the slug front arrives at the riser 
top the riser DP reaches its maximum and then remains roughly constant for a period (slug production stage). At this stage the slug tail in the pipeline moves towards the riser base and the slug front at the riser top moves to the topside separator. The liquid slug is hence longer than the riser. The gas-blowdown/liquid-fallback stage starts when the gas bubbles behind the slug tail continuously come into the riser. At this stage the liquid slug is swept out of the riser violently and then the gas rushes into the topside separator at a high velocity and the riser DP decreases sharply to its minimum.

Transitional Severe Slugging (TSS): At the liquid buildup stage the slug length increases only in the riser but no liquid backup in the pipeline can be found. The gas in the pipeline penetrates into the slug in the riser just as the slug front arrives at the riser top. Hence the slug length is approximately equal to the length of the riser. The maximum riser DP is almost the same with that of severe slugging, but it does not remain constant for a period of time for slug production. The TSS is characterised by the absence of the slug production stage compared with SS.

Oscillation Flow (OSC): At the liquid buildup stage the gas and liquid move into the riser alternatively, thus more than one aerated slugs coexist in the riser separated by gas packets. (In the discussions below a slug of the same length with the sum of the slugs is considered as an equivalent of them.) This stage ends when the front of the first slug arrives at the riser top and a gas blowdown stage follows immediately. The riser DP still exhibits cyclic behaviour, although the maximum is lower than those of SS and TSS.

Continuous Flow (CON): The gas and liquid come into the riser continuously. No obvious 'liquid buildup' stages can be observed. The flow regimes in the riser are mainly slug flow with Taylor bubbles or churn flow. The riser DP remains roughly constant with irregular fluctuations of small amplitudes.

\subsection{Characteristic parameters}

The long liquid slugs in SS and TSS are most problematic to the downstream facilities of the pipeline/riser production system. In OSC the liquid slug is shorter than the riser; however, the induced pressure fluctuations in the pipeline still challenge the stability of the whole production system.

In general, the severity of SS is higher than TSS and OSC is the lowest. In order to characterise the flow behaviour of the SS, TSS and OSC flow regimes and evaluate the performance of different wavy pipes qualitatively, a series of characteristic parameters (CPs) are defined. The CPs include two groups of parameters based on the analysis of the riser DP time traces, i.e. magnitude parameters $\left(M_{\mathrm{MAX}}, M_{\mathrm{MIN}}, M_{\mathrm{AMP}}\right.$ and $\left.M_{\mathrm{AVE}}\right)$ and time parameters ( $T_{\mathrm{BUI}}, T_{\mathrm{PRO}}, T_{\mathrm{BFB}}$ and $\left.T_{\mathrm{CYC}}\right)$. The $M_{\mathrm{MAX}}, M_{\mathrm{MIN}}, M_{\mathrm{AMP}}$ and $M_{\mathrm{AVE}}$ refer to the maximum, minimum, fluctuation amplitude and time average of the riser DP, respectively; while the $T_{\mathrm{BUI}}, T_{\mathrm{PRO}}, T_{\mathrm{BFB}}$ and $T_{\mathrm{CYC}}$ are the time periods of the liquid buildup stage, slug production stage, bubble-penetration/gasblowdown/liquid-fallback stages and total cycle time, respectively.

The CPs can be used to assess the severity of the flow regimes qualitatively. For SS and TSS the $M_{\mathrm{MAX}}$ is generally equal to the hydrostatic pressure of the liquid column filling the riser. For OSC the $M_{\mathrm{MAX}}$ can be treated as the consequence of the 
maximum equivalent slug length in the riser. The $M_{\mathrm{MIN}}$ indicates how much liquid has been left in the riser after the gas-blowdown/liquid-fallback stage. The $M_{\mathrm{AMP}}$ is an indicator of the length of the slug produced out of the riser at the gas blowdown stage. The $M_{\mathrm{AVE}}$ is used to calculate the average pressure at the riser base. The riser base pressure should be as low as possible to obtain as much production from the supply source as possible. The $T_{\mathrm{BUI}}$ is an indicator of the slug front velocity at the liquid buildup stage. The average velocity can be estimated in conjunction with the $M_{\text {MAX }}$ and $M_{\mathrm{MIN}}$. The $T_{\mathrm{PRO}}$ is only valid for SS, which indicates how long it takes for the severe slug to be produced at the slug production stage. At the same flowrates of gas and liquid, the longer the $T_{\mathrm{PRO}}$ is the longer the severe slug is produced and the more severe the flow regime is. Similar to the $T_{\mathrm{PRO}}$ the $T_{\mathrm{BFB}}$ can be used to estimate the average slug velocity at the gas blowdown stage. The inverse of the $T_{\mathrm{CYC}}$ can be regarded as the slug frequency of the severe slugs for SS/TSS and the equivalent slugs for OSC.

\section{Effects of wavy pipes on the flow in pipeline/riser systems}

The effects of the wavy pipe on the flow behaviour in pipeline/riser systems have been inspected in terms of the flow regime and characteristic parameters of the riser DP defined in Section 3. The working principle to account for the effects of the wavy pipe on the flow has been presented.

\subsection{Effects on flow regimes}

The basic flow regime map with superficial gas and liquid velocities as coordinates is divided into two regions: Region I and II. Region I is the SS region, whereas Region II includes OSC and CON. In the flow regime map discussed below, a boundary (also called stability boundary) is placed between Region I and Region II, where TSS is expected to occur. It needs to be noted that TSS did not appear explicitly in the designed test matrix at some superficial liquid velocities. To obtain a stability boundary TSS was assumed to occur at a $U_{\mathrm{SG} 0}$ located in the middle of the last SS case and the first OSC case with the increase of $U_{\mathrm{SG} 0}$ at the same $U_{\mathrm{SL}}$.

Fig. 6 shows the stability boundaries for the 2" and 4" pipeline/riser and pipeline/wavy-pipe/riser systems of test configuration CI. Region I and Region II are located on the left and right side of the stability boundary, respectively. It can be seen that Region I is reduced with the wavy pipe applied. The stability boundary is shifted towards the lower superficial gas velocity, $U_{\mathrm{SG} 0}$, by up to $0.4 \mathrm{~m} / \mathrm{s}$ and $0.5 \mathrm{~m} / \mathrm{s}$ for the 2 " and 4" systems, respectively. The flow regimes of the test cases located between the two boundaries (with and without a wavy pipe) are SS in the pipeline/riser system, but have become OSC in the pipeline/wavy-pipe/riser system.

Fig. 7 shows the stability boundaries for the 2" pipeline/riser and pipeline/wavypipe/riser systems with the wavy pipe outlet located at the riser base and upstream of the riser base. Fig. 7 (a) and (b) illustrate the stability boundaries for the wavy pipes of 7 and 11 bends, respectively. It can be seen that Region I can be further reduced with the outlet of the wavy pipe moved upstream of the riser base. Comparing Fig. 7 (a) and (b) we can see that, for the cases with $U_{\mathrm{SL}}$ between $0.6 \mathrm{~m} / \mathrm{s}$ and $0.8 \mathrm{~m} / \mathrm{s}$, the stability boundary with the 11-bend wavy pipe appears at lower $U_{\mathrm{SG}}$. 
The flow regime transition boundary between SS and OSC can be shifted towards the SS region when a wavy pipe is installed in the pipeline upstream of the riser; consequently the region in the flow regime map for SS to occur is reduced. The location of the wavy pipe relative to the riser base has significant effects on its performance. The wavy pipe is more effective when there is a pipe section of an appropriate length between its outlet and the riser base. A smaller SS region can be obtained with a longer wavy pipe (of more bends).

\subsection{Effects on characteristic parameters}

The $M_{\mathrm{MAX}}, M_{\mathrm{MIN}}$ and $M_{\mathrm{AVE}}$ of the riser DP have been plotted against the superficial gas velocity $\left(U_{\mathrm{SG} 0}\right)$ at fixed superficial liquid velocities $\left(U_{\mathrm{SL}}\right)$ for different test configurations. Fig. 8 (a) and (b) show the plots for $U_{\mathrm{SL}}=0.25 \mathrm{~m} / \mathrm{s}$ and $0.86 \mathrm{~m} / \mathrm{s}$, respectively. The $M_{\mathrm{MAX}}$ of the riser DP are almost the same for the SS cases because the riser can be filled with the liquid. For the OSC cases the $M_{\mathrm{MAX}}$ is the highest in the pipeline/riser system consistently and the lowest $M_{\mathrm{MAX}}$ appears in the pipeline/wavypipe/riser system with the 11-bend wavy pipe located at $1.5 \mathrm{~m}$ upstream of the riser base. The effects of the wavy pipes on the $M_{\mathrm{MIN}}$ of the riser DP are not significant for $\mathrm{SS}$ and OSC. However, the critical $U_{\mathrm{SG} 0}$ for CON to occur is much lower in the pipeline/wavy-pipe/riser systems than that in the pipeline/riser system as shown in Fig. 8 (b). The $M_{\mathrm{AVE}}$ of the riser DP decreases with the increase of $U_{\mathrm{SG} 0}$ monotonously. The variation of the $M_{\mathrm{MAX}}, M_{\mathrm{MIN}}$ and $M_{\mathrm{AVE}}$ of the riser DP with the increase of $U_{\mathrm{SL}}$ for SS at $U_{\mathrm{SG} 0}=0.70 \mathrm{~m} / \mathrm{s}$ is shown in Fig. 8 (c). All of the $M_{\mathrm{MAX}}$, $M_{\mathrm{MIN}}$ and $M_{\mathrm{AVE}}$ increase with the increase of $U_{\mathrm{SL}}$. The increase of the $M_{\mathrm{MAX}}$ is a result of the increase of the frictional pressure drop in the riser. The increase of the $M_{\mathrm{MIN}}$ results from the increase of the liquid amount left in the riser after the gasblowdown/liquid-fallback stage. At the same $U_{\mathrm{SG} 0}$ more liquid tends to be left in the riser at higher $U_{\mathrm{SL}}$ due to the limited energy from the gas expansion. The $M_{\mathrm{AVE}}$ increases due to the increase of both of the $M_{\mathrm{MAX}}$ and $M_{\mathrm{MIN}}$. The $M_{\mathrm{AVE}}$ in pipeline/wavy-pipe/riser systems is consistently lower than that in the pipeline/riser system. For the SS cases the decrease of the $M_{\mathrm{AVE}}$ results from the reduction of the slug length and slug production time. For the OSC cases the decrease of the $M_{\mathrm{AVE}}$ is induced by the decrease of the $M_{\mathrm{MAX}}$ of the riser DP, i.e. the reduction of the maximum equivalent slug length.

The $M_{\mathrm{AMP}}$ is an indicator of the length of the severe slug for SS and the equivalent slug for OSC produced from the riser at the gas blowdown stage. The variations of the $M_{\mathrm{AMP}}$ of the riser DP for different test configurations are illustrated in Fig. 9 at constant $U_{\mathrm{SL}}\left((\mathbf{a})\right.$ and (b)) and $U_{\mathrm{SG} 0}((\mathbf{c}))$, respectively. It can be observed in Fig. 9 (a) and (b) that the variations of the $M_{\mathrm{AMP}}$ with the increase of $U_{\mathrm{SG} 0}$ are different at the lower and higher $U_{\mathrm{SL}}$. At the lower $U_{\mathrm{SL}}\left(U_{\mathrm{SL}}=0.25 \mathrm{~m} / \mathrm{s}\right)$ the $M_{\mathrm{AMP}}$ fluctuates slightly for SS and decreases significantly for OSC; at the higher $U_{\mathrm{SL}}\left(U_{\mathrm{SL}}=0.86 \mathrm{~m} / \mathrm{s}\right)$ the $M_{\mathrm{AMP}}$ increases for SS and decreases for OSC. The $M_{\mathrm{AMP}}$ for OSC in the pipeline/wavy-pipe/riser systems is consistently lower than that in the pipeline/riser system, showing that the maximum equivalent slug length for OSC is reduced with a wavy pipe applied. The lowest $M_{\mathrm{AMP}}$, corresponding to the shortest maximum equivalent slug, is obtained with the outlet of the 11-bend wavy pipe located at $1.5 \mathrm{~m}$ upstream of the riser base in the experiment. As can be seen in Fig. 9 (c) the $M_{\text {AMP }}$ decreases approximately linearly with the increase of $U_{\mathrm{SL}}$ for the SS cases. The reduction of the $M_{\mathrm{AMP}}$ indicates that the slug produced from the riser at the gas 
blowdown stage becomes shorter with the increase of $U_{\mathrm{SL}}$. No obvious effects of the test configurations of the wavy pipes on the relationship between the $M_{\mathrm{AMP}}$ and $U_{\mathrm{SL}}$ can be found for SS.

As presented in Section 4.1 the SS region in the flow regime map can be reduced with a wavy pipe applied, however, there is still a region for SS to occur. In this smaller region the severity of the flow can be reduced in terms of the slug length reduction. The $T_{\mathrm{PRO}}$ is an indicator of the length of the severe slug produced from the riser at the slug production stage. The riser DP time traces of a sample SS case for different test configurations (2" system) are compared in Fig. 10. The average $T_{\mathrm{PRO}}$ are $181.5 \mathrm{~s}, 66$ s, $58 \mathrm{~s}, 88 \mathrm{~s}$ and $79.5 \mathrm{~s}$ for the pipeline/riser, 7-bend wavy pipe of CI and CII, 11-bend wavy pipe of CIII and CIV, respectively. The longer the $T_{\mathrm{PRO}}$ is the longer the produced severe slug at the slug production stage is. The smallest $T_{\mathrm{PRO}}$ is obtained with the 7-bend wavy pipe located $1.5 \mathrm{~m}$ away from the riser base. Fig. 11 shows the variation of the $T_{\mathrm{PRO}}$ with the increase of $U_{\mathrm{SL}}$ at $U_{\mathrm{SG} 0}=0.70 \mathrm{~m} / \mathrm{s}$. It can be observed that: (1) the $T_{\mathrm{PRO}}$ for the pipeline/riser system is much larger than those for the pipeline/wavy-pipe/riser systems; (2) the $T_{\mathrm{PRO}}$ for the pipeline/11-bend-wavypipe/riser systems are larger than those for the pipeline/7-bend-wavy-pipe/riser systems; (3) the $T_{\mathrm{PRO}}$ for the pipeline/wavy-pipe/riser systems with the outlet of the wavy pipe located at the riser base are larger than those with the outlet upstream of the riser base. Therefore, the shortest severe slug produced from the riser at the slug production stage is obtained by employing a 7-bend wavy pipe with its outlet located upstream of the riser base.

The SS flow regime is a cyclic process. The cycle time of SS can be obtained by examining the average cycle time $\left(T_{\mathrm{CYC}}\right.$ ) of the riser DP. The $T_{\mathrm{CYC}}, T_{\mathrm{BUI}}$ and $T_{\mathrm{BFB}}$ are plotted against $U_{\mathrm{SL}}$ in Fig. 12 (a), (b) and (c), respectively. The $T_{\mathrm{CYC}}$ decreases with the increase of $U_{\mathrm{SL}}$ at the same $U_{\mathrm{SG} 0}$ and the relationship between them is approximately linear. With a wavy pipe applied the $T_{\mathrm{CYC}}$ is reduced by more than $40 \%$ of that for the pipeline/riser system. A smaller $T_{\mathrm{CYC}}$ means a higher slug frequency. A higher slug frequency results in shorter slugs. Therefore, the slug length in the pipeline/riser system can be reduced with a wavy pipe. The $T_{\mathrm{BUI}}$ decreases with the increase of $U_{\mathrm{SL}}$ at the same $U_{\mathrm{SG} 0}$. At the lower $U_{\mathrm{SL}}\left(U_{\mathrm{SL}}<0.4 \mathrm{~m} / \mathrm{s}\right)$ the $T_{\mathrm{BUI}}$ for the pipeline/riser system is larger than those for the pipeline/wavy-pipe/riser systems. At the higher $U_{\mathrm{SL}}\left(U_{\mathrm{SL}}>0.4 \mathrm{~m} / \mathrm{s}\right)$ no significant effects of the test configurations of the wavy pipe on the $T_{\mathrm{BUI}}$ can be observed. The $T_{\mathrm{BFB}}$ for the SS cases varies between $10 \mathrm{~s}$ and $30 \mathrm{~s}$. Neither the $U_{\mathrm{SL}}$ nor the wavy pipe has consistent effects on the $T_{\mathrm{BFB}}$.

Essentially all the effects of wavy pipes can be regarded as reducing the slug length in the pipeline/riser system. When SS is transformed into OSC with a wavy pipe applied, the long severe slug (longer than the riser) has been split into more than one shorter slugs (shorter than the riser). A lower $M_{\mathrm{MAX}}$ and $M_{\mathrm{AMP}}$ of OSC mean a shorter maximum equivalent slug and shorter slugs produced from the riser at the gas blowdown stage, respectively. A smaller $T_{\mathrm{PRO}}$ means a shorter slug produced from the riser at the slug production stage and a smaller $T_{\mathrm{CYC}}$ indicates a higher slug frequency. A higher slug frequency results in shorter slugs in the pipeline/riser system because the inlet mass flowrates of gas and liquid are the same for different test configurations.

\subsection{Working principle of wavy pipes}


It has been concluded above that the effects of wavy pipes can be regarded as reducing the slug length. Three scenarios of the slug length reduction are discussed below to disclose the working principle of wavy pipes.

(1) Scenario I: SS in both of the pipeline/riser and pipeline/wavy-pipe/riser systems;

(2) Scenario II: SS in the pipeline/riser system but OSC in the pipeline/wavypipe/riser system;

(3) Scenario III: OSC in both of the pipeline/riser and pipeline/wavy-pipe/riser systems.

There are four stages in one SS cycle, i.e. liquid buildup stage, slug production stage, bubble penetration stage and gas-blowdown/liquid-fallback stage, but only two stages, i.e. liquid buildup and gas blowdown stages, for OSC. The flow behaviour in the three scenarios is described for the different stages individually. The schematics of the pipeline/riser system and pipeline/wavy-pipe/riser system are shown in Fig. 13 (a) and (b), respectively.

\section{Scenario I: SS to SS}

The SS has not been changed into OSC with a wavy pipe applied at a range of lower superficial gas and liquid velocities. However, the length of the severe slug is reduced instead. Thus the severity of SS is mitigated with a wavy pipe. A typical SS case with a long severe slug is discussed in Scenario I. The slug tail arrives at the upstream of the wavy pipe at the end of the liquid buildup stage.

Fig. 14 compares the phase distribution upstream of the riser base in the pipeline/riser and pipeline/wavy-pipe/riser systems. At the liquid buildup stage of SS the gas is compressed upstream of the slug tail in the pipeline/riser system and there is no gas entrainment in the slug body in the pipeline. However, a certain amount of gas is usually trapped in the wavy pipe and the pipe section between the riser base and wavy pipe outlet in the pipeline/wavy-pipe/riser system. As a result, the severe slug in the pipeline is separated into several portions by the trapped gas.

At the slug production stage the slug tail in the pipeline moves towards the riser base. In the pipeline/riser system all the gas coming from the pipeline inlet moves behind the whole slug body slowly and the bubble penetration stage is initiated by the gas behind the slug tail, while it is initiated by the trapped gas in the pipeline/wavypipe/riser system. While the slug body is moving upwards along the riser, the trapped gas in the pipe section between the riser base and wavy pipe outlet arrives at the riser base first. With the accumulation of the trapped gas at the riser base the gas pressure increases. Once the gas pressure becomes high enough, several gas bubbles penetrate into the riser. The penetration of the bubbles results in a reduction of the hydrostatic pressure induced by the liquid column in the riser. The reduction of the hydrostatic pressure allows the trapped gas in the wavy pipe and behind the slug tail to move to the riser base more quickly. As more and more gas accumulates at the riser base the bubble penetration stage is initiated and the slug production stage ends. It takes less time for the trapped gas to be transferred into the riser, thus the slug production stage ends before the arrival of the slug tail at the riser base in the pipeline/wavy-pipe/riser system. 
The slug body in the pipeline is split into several portions by the trapped gas at the liquid buildup stage with a wavy pipe applied; the trapped gas in the slug body in the pipeline initiates the bubble penetration stage earlier than that in the pipeline/riser system. As a result, a smaller slug production stage time and shorter liquid slug can be obtained in the pipeline/wavy-pipe/riser system than those in the pipeline/riser system.

\section{Scenario II: SS to OSC}

The SS in the pipeline/riser system has been changed into OSC with a wavy pipe at a certain range of superficial gas and liquid velocities. This scenario takes place when the severe slug in the pipeline is short enough and the slug tail is located between the riser base and the wavy pipe inlet as shown in Fig. 15.

Similar to the SS case in the pipeline/wavy-pipe/riser system in Scenario I, there is also some gas trapped in the pipe section between the riser base and wavy pipe outlet and in the humps of the $\Lambda$ sections at the liquid buildup stage. The difference is that the slug tail is located downstream of the wavy pipe inlet. Because there is no continuous distribution of the liquid phase in the wavy pipe, the actual slug tail can be regarded to be located between the riser base and wavy pipe outlet rather than the location indicated in Fig. 15. Hence the slug in the pipeline/wavy-pipe/riser system is smaller than that in the pipeline/riser system at the same operating conditions. Furthermore, a shorter liquid slug in the pipeline allows the upstream gas to be closer to the riser base. As a result, the compressed gas in the pipeline moves into the riser before the arrival of the slug front at the riser top. Therefore, there is no chance for a slug longer than the riser, i.e. severe slug, to form. Consequently the SS in the pipeline/riser system is changed into OSC in the pipeline/wavy-pipe/riser system.

\section{Scenario III: OSC to OSC}

The OSC prevails in the pipeline/riser system at a range of higher superficial gas and liquid velocities. The equivalent slug of OSC in the pipeline/wavy-pipe/riser system is shorter than that in the pipeline/riser system. Thus the severity of the OSC can be reduced with a wavy pipe applied.

In the pipeline/riser system the flow regime in the downwardly inclined pipeline is stratified flow at different stages of OSC. At the liquid buildup stage the liquid tends to accumulate at the riser base and then the liquid is pushed into the riser by the upstream gas. In this way several short slugs form at the riser base and then coexist in the riser at the liquid buildup stage. However, the stratified flow no longer persists in the pipeline when there is a wavy pipe upstream of the riser base. The gas/liquid two phases are churned up by the $\Lambda$ and V sections of the wavy pipe. As a result, the flow at the outlet of the wavy pipe becomes into highly aerated slug flow or even homogenous flow. Hence a mixture of the gas/liquid two phases instead of two separated phases arrives at the riser base. Therefore, the possibility for the liquid slugs as long as those in the pipeline/riser system to form at the riser base is reduced significantly. Consequently the maximum equivalent length of the slugs coexisting in the riser is reduced for the OSC with a wavy pipe in place.

The wavy pipe works by reducing the length of the severe slug and equivalent slug for 
SS and OSC, respectively. For SS the wavy pipe acts as an 'accelerator' which can accelerate the movement of the gas in the pipeline to the riser, as a result, both of the slug production time and the length of the severe slug can be reduced. The SS is changed into OSC when the slug production time is zero and the slug is shorter than the riser. For OSC the wavy pipe acts as a 'mixer' which mixes the gas/liquid two phases and turns the stratified flow in the pipeline into highly aerated slug flow or even homogenous flow moving towards the riser base. Thus even shorter slugs than those without a wavy pipe tend to form at the riser base and in the riser.

\section{Discussions}

\subsection{Location of the wavy pipe}

It has been demonstrated in Section 4 that a smaller SS region and shorter $T_{\mathrm{PRO}}$ than those in the pipeline/riser system can be obtained with a wavy pipe applied. The wavy pipe is more effective on reducing the slug length when there is a pipe section between the riser base and wavy pipe outlet.

As identified in Scenario I and II in Section 4.3, a certain amount of gas is trapped in the slug body in the pipeline at the liquid buildup stage. When the outlet of the wavy pipe is located at the riser base the gas is only trapped in the humps of the wavy pipe; when there is a pipe section between the riser base and wavy pipe outlet, some gas is also trapped in that pipe section. Hence more gas can be trapped in the slug body in the pipeline when the wavy pipe outlet is located at a distance away from the riser base than at the riser base. To initiate the bubble penetration stage it is required that there is enough amount of gas at the riser base and the pressure of the gas is high enough. Therefore, with more trapped gas in the pipe section between the riser base and wavy pipe outlet, it takes less time for the required gas to be collected and compressed at the riser base to initiate the bubble penetration stage. As a result, the slug production time, $T_{\mathrm{PRO}}$, can be reduced further compared with that with the outlet of the wavy pipe located at the riser base. When the $T_{\mathrm{PRO}}$ is reduced to zero, the SS is transformed into TSS or even OSC. However, it needs to be noted that the pipe section between the riser base and wavy pipe outlet is restricted by the slug length, because the slug tail should be located in the wavy pipe or upstream of the wavy pipe.

\subsection{Length of the wavy pipe}

Two wavy pipes of different lengths, i.e. 7 and 11 bends, have been tested on the 2" pipeline/riser system. The experimental data presented in Section 4 have shown that lower $M_{\mathrm{MAX}}$ and $M_{\mathrm{AMP}}$ for the OSC flow, indicating a shorter equivalent slug in the riser, are obtained with a longer wavy pipe applied.

The wavy pipe acts as a 'mixer' for OSC as concluded in Section 4.3. A longer wavy pipe with more $\Lambda$ and $\mathrm{V}$ sections is able to agitate the gas/liquid two phases more effectively. The mixture of the gas/liquid two phases tends to be more 'homogeneous' and the slugs forming at the riser base are even shorter. Hence the equivalent slug length in the riser is reduced further for OSC with a longer wavy pipe of more bends. As a result, the $M_{\mathrm{MAX}}$ and $M_{\mathrm{AMP}}$ are lower in the pipeline/11-bend-wavy-pipe/riser system than those in the pipeline/7-bend-wavy-pipe/riser system. 


\section{Conclusions}

Wavy pipes have been used as flow conditioners for mitigating severe slugging in pipeline/riser systems. A series of experiments were conducted on a group of test configurations: 2" and 4" pipeline/riser systems, pipeline/wavy-pipe/riser systems with the wavy pipe at different locations in the pipeline, pipeline/wavy-pipe/riser systems with the wavy pipe of different lengths (different number of bends). The performance of the wavy pipe on severe slugging mitigation has been presented in terms of the flow regime transition and characteristic parameters of the flow behaviour. The working principle and the effects of the geometrical parameters and location in the pipeline of the wavy pipe have been disclosed.

(1) The flow regimes in the pipeline/riser systems can be classified into four categories: severe slugging, transitional severe slugging, oscillation flow and continuous flow. They appear in sequence with the increasing gas flowrate at a fixed liquid flowrate.

(2) The severe slugging region in the flow regime map can be reduced by applying a wavy pipe in the pipeline. Even if there is no flow regime transition from severe slugging to oscillation flow due to the application of a wavy pipe, the severity of severe slugging and oscillation flow can also be reduced. The time-average differential pressure across the riser in the pipeline/wavy-pipe/riser systems is consistently lower than that in the pipeline/riser system without a wavy pipe.

(3) The location of the wavy pipe relative to the riser base has significant effects on its performance. The wavy pipe is more effective when there is a pipe section of an appropriate length between its outlet and the riser base.

(4) The effects of the wavy pipe are concluded to be reducing the slug length in the pipeline/riser system. For severe slugging the wavy pipe works by accelerating the movement of the gas phase in the pipeline to the riser base to initiate the bubble penetration stage; for the oscillation flow the wavy pipe works by mixing the gas/liquid two phases.

\section{Acknowledgements}

The authors would like to express sincere thanks to the financial support and permission to publish this work from Chevron Energy Technology Company. The financial support from the Overseas Research Students Awards Scheme (ORSAS) and Cranfield University is also acknowledged.

\section{References}

Almeida, A. R., Gonçalves M. A. L., 1999. Venturi for severe slugging elimination. Proceedings of the $9^{\text {th }}$ International Conference on Multiphase Production, BHRg, 149-158.

Bai, Y., Bai, Q., 2005, Subsea pipelines and risers, second ed. Elsevier Science Ltd. 
Brown, L. D., 2002. Flow assurance: a $\pi 3$ discipline. Proceedings of the Annual Offshore Technology Conference, 183-189.

Guo, B., Song, S., Chacko, J., Ghalambor, A., 2005. Offshore pipelines. Elsevier Science Ltd.

Havre, K., Dalsmo, M., 2002. Active feedback control as a solution to severe slugging. SPEPF17 (3), 138-148.

Jansen, F.E., Shoham, O., Taitel, Y., 1996. The elimination of severe slugging experiments and modeling. Int. J. Multiphase Flow 22 (6), 1055-1072.

Lee, J., 2009. Introduction to offshore pipelines and risers. 2009C Revision, http://www.jylpipeline.com/Pipeline_2009C_Brief.pdf. Last accessed on $1^{\text {st }}$ November 2010.

Linga, H., 1987. Terrain slugging phenomena: some experimental results obtained at the SINTEF two-phase flow laboratory. Proceedings of the $3^{\text {rd }}$ International Conference on Multiphase Production, BHRg, 37-53.

Makogan, T. Y., Brook G. J., 2007. Device for controlling slugging. WO 2007/034142.

Sarica, C., Tengesdal, J. O., 2000. A new technique to eliminate severe slugging in pipeline/riser systems. Paper SPE 63185 presented at the SPE Annual Technical Conference and Exhibition, Dallas, Texas, USA, 1-4 October.

Schmidt, Z., Brill, J. P., Beggs, H. D., 1980. Experimental study of severe slugging in a two-phase-flow pipeline-riser pipe system. SPEJ 20(5), 407-414.

Schmidt, Z, Doty, D. R., Dutta-Roy, K., 1985. Severe slugging in offshore pipelineriser pipe system. SPEJ 25 (1), 27-38.

Sivertsen, H., Storkaas, E., Skogestad, S., 2010. Small-scale experiments on stabilizing riser slug flow. Chem Eng Res Des, 88 (2), 213-228.

Storkaas, E., 2005. Stabilizing control and controllability: control solutions to avoid slug flow in pipeline-riser systems. PhD Thesis, Norwegian University of Science and Technology, Norway.

$\mathrm{Su}$, J., 2003. Flow assurance of deepwater oil and gas production - a review. Proceedings of OMAE-03, $22^{\text {nd }}$ International Conference on Offshore Mechanics and Arctic Engineering; Safety and Reliability Pipeline Technology, 601-620.

Taitel Y., 1986. Stability of severe slugging. Int. J. Multiphase Flow 12 (2), 203-217.

Taitel, Y., Vierkandt, S., Shoham, O., Brill, J.P., 1990. Severe slugging in a riser system: experiments and modeling. Int. J. Multiphase Flow 16(1), 57-68.

Tin, V., 1991. Severe slugging in flexible risers. Proceedings of the $5^{\text {th }}$ International Conference on Multiphase Production, BHRg, 507-525. 
Watson, M. J., Pickering, P. F., Hawkes, N. J., 2003. The flow assurance dilemma: risks vs. costs. Hart's E \& P 76 (5), 36-40.

Yocum, B.T., 1973. Offshore riser slug flow avoidance, mathematical model for design and optimization. Paper SPE 4312 presented at SPE European Meeting, London, UK, 2-3 April. 


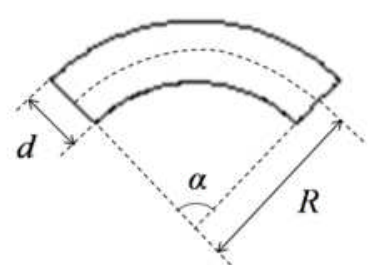

(a) bend

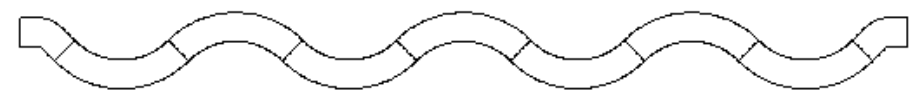

(b) wavy pipe of 7 bends

Fig. 1 Parameters of a bend and schematic of a wavy pipe

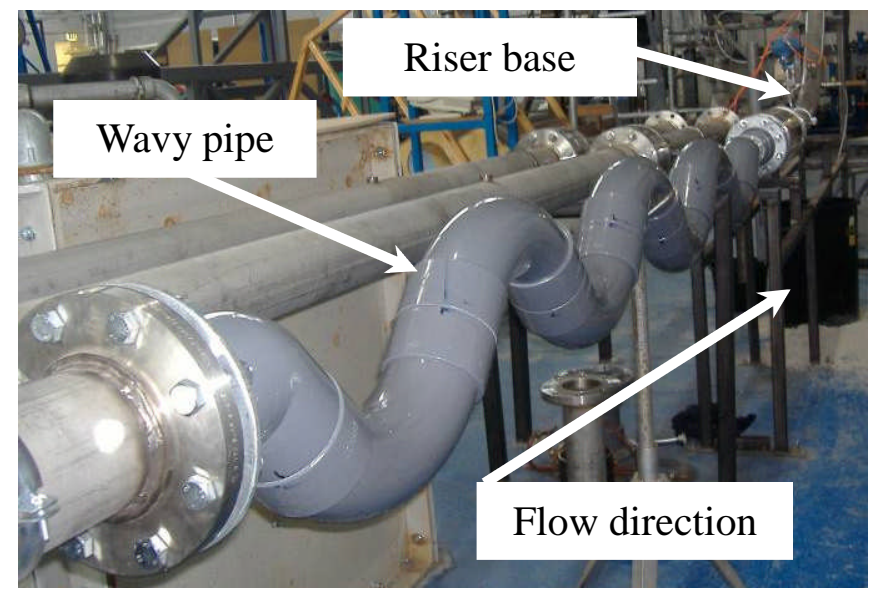

Fig. 2 Photograph of the 4" wavy pipe of 7 bends in the pipeline

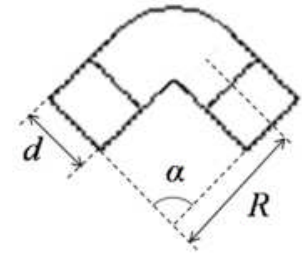

(a) 2" bend

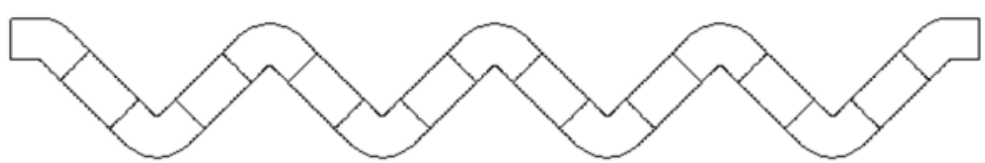

(b) 2" wavy pipe of 7 bends

Fig. 3 Parameters of a 2" bend and schematic of a 2" wavy pipe of 7 bends 


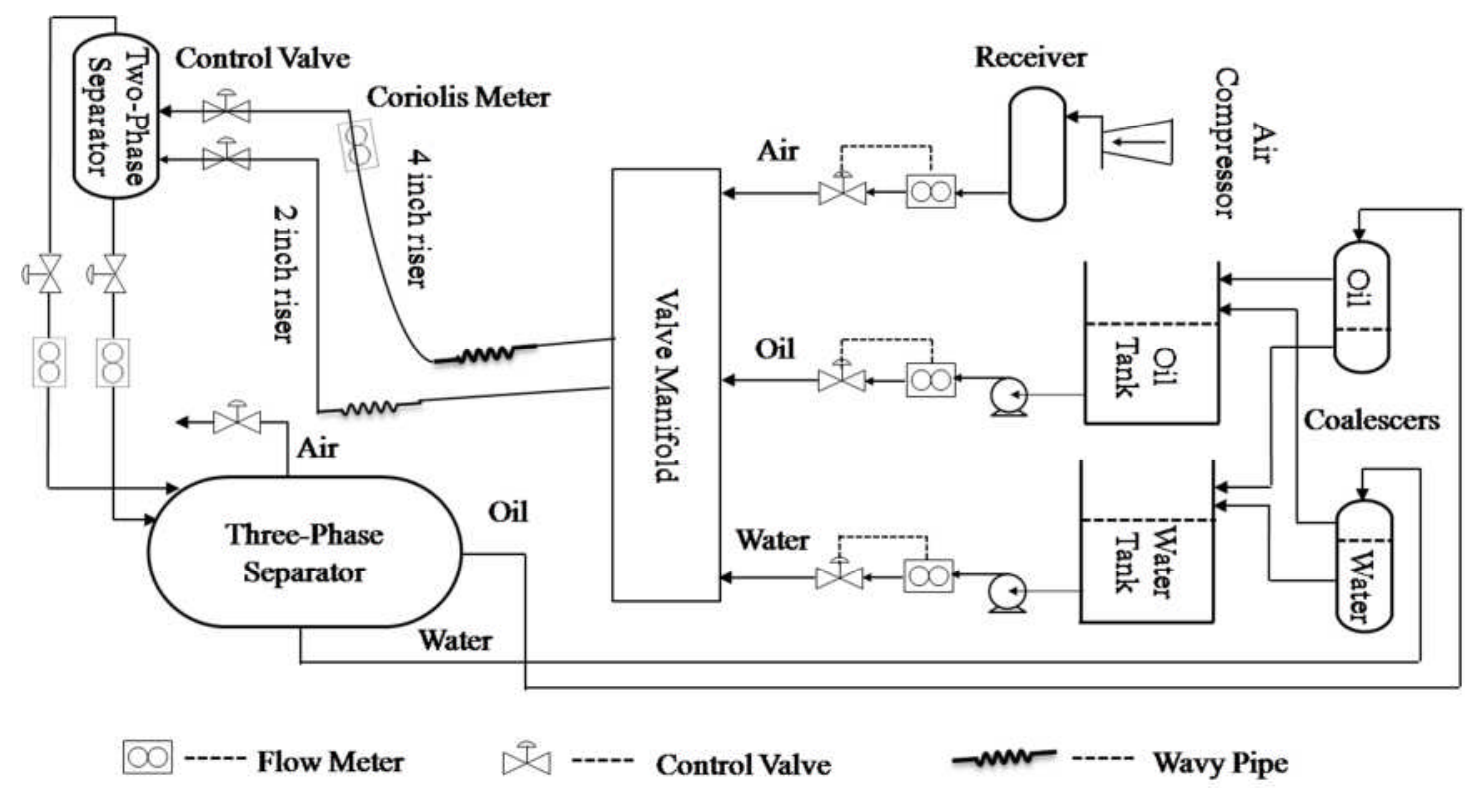

Fig. 4 Schematic of the Three-Phase Test Facility with 2" and 4" pipeline/riser systems

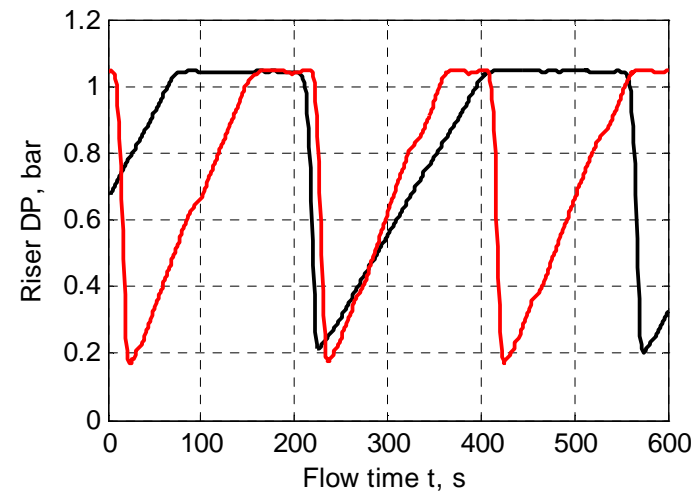

(a) SS and SS: $U_{\mathrm{SG} 0}=0.70 \mathrm{~m} / \mathrm{s}$

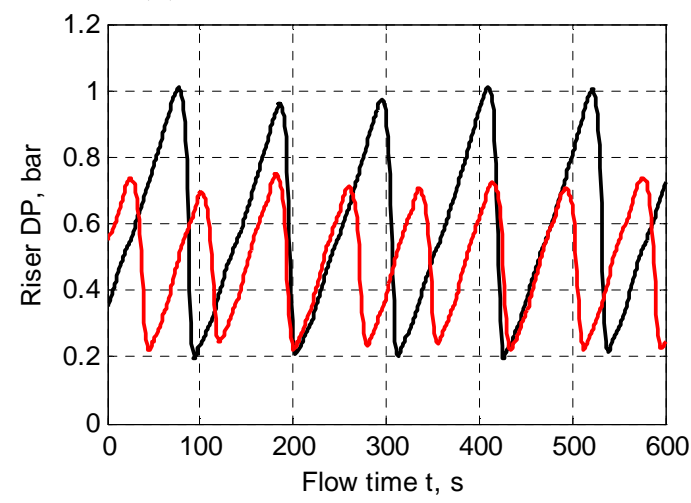

(c) OSC and OSC: $U_{\mathrm{SG} 0}=1.41 \mathrm{~m} / \mathrm{s}$

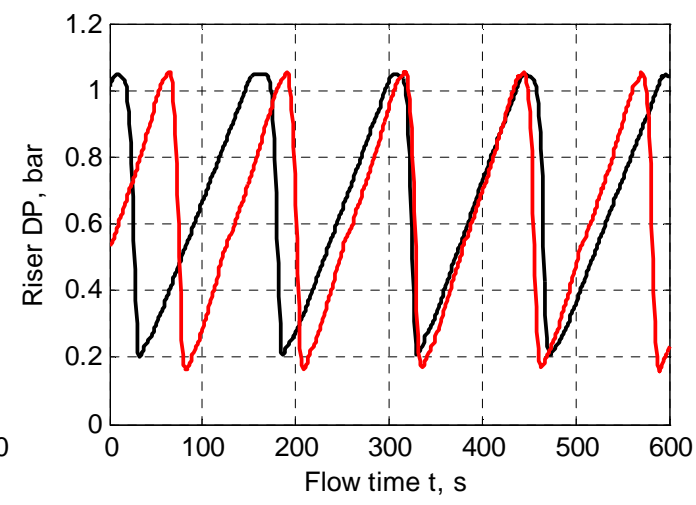

(b) SS and TSS: $U_{\mathrm{SG} 0}=1.06 \mathrm{~m} / \mathrm{s}$

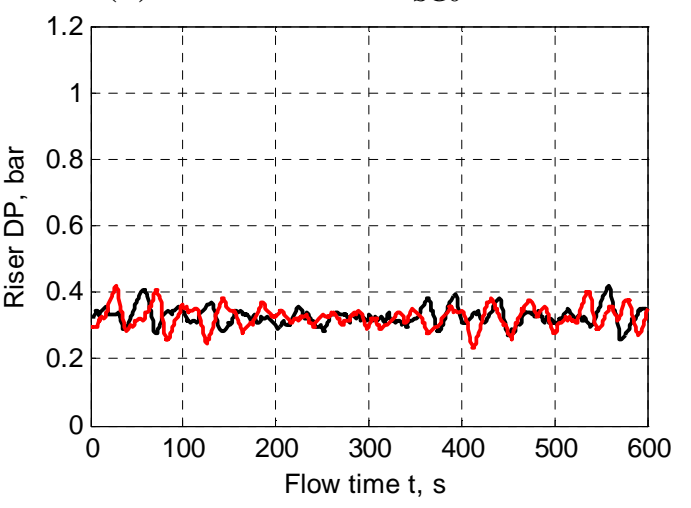

(d) $\mathrm{CON}$ and CON: $U_{\mathrm{SG} 0}=2.82 \mathrm{~m} / \mathrm{s}$

Plain riser system

Pipeline/wavy-pipe/riser system

Fig. 5 Riser DP time traces of severe slugging (SS), transitional severe slugging (TSS), oscillation flow (OSC) and continuous flow $(\mathrm{CON})$ at $U_{\mathrm{SL}}=0.12 \mathrm{~m} / \mathrm{s}$ 


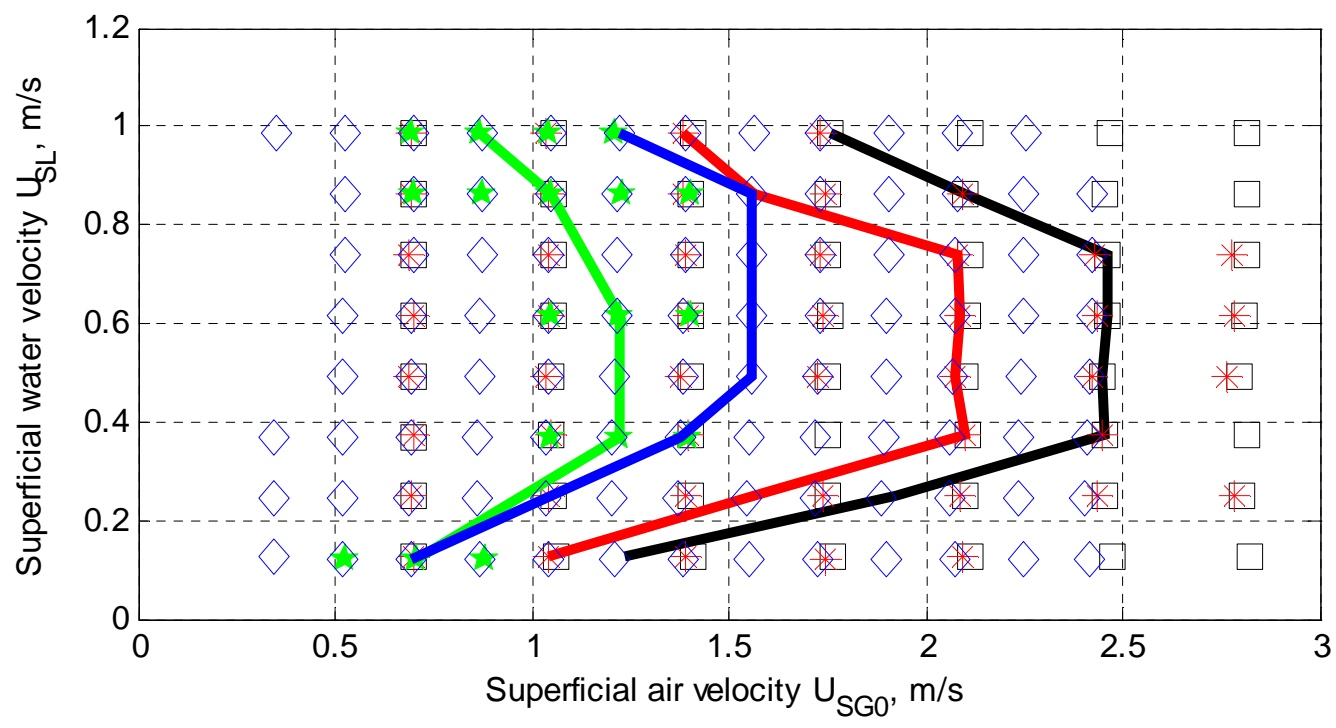

- 2" plain riser system — 2" pipeline/wavy-pipe/riser system 4" plain riser system 4" pipeline/wavy-pipe/riser system

Fig. 6 Stability boundaries for the 2" and 4" plain riser and pipeline/wavypipe/riser systems

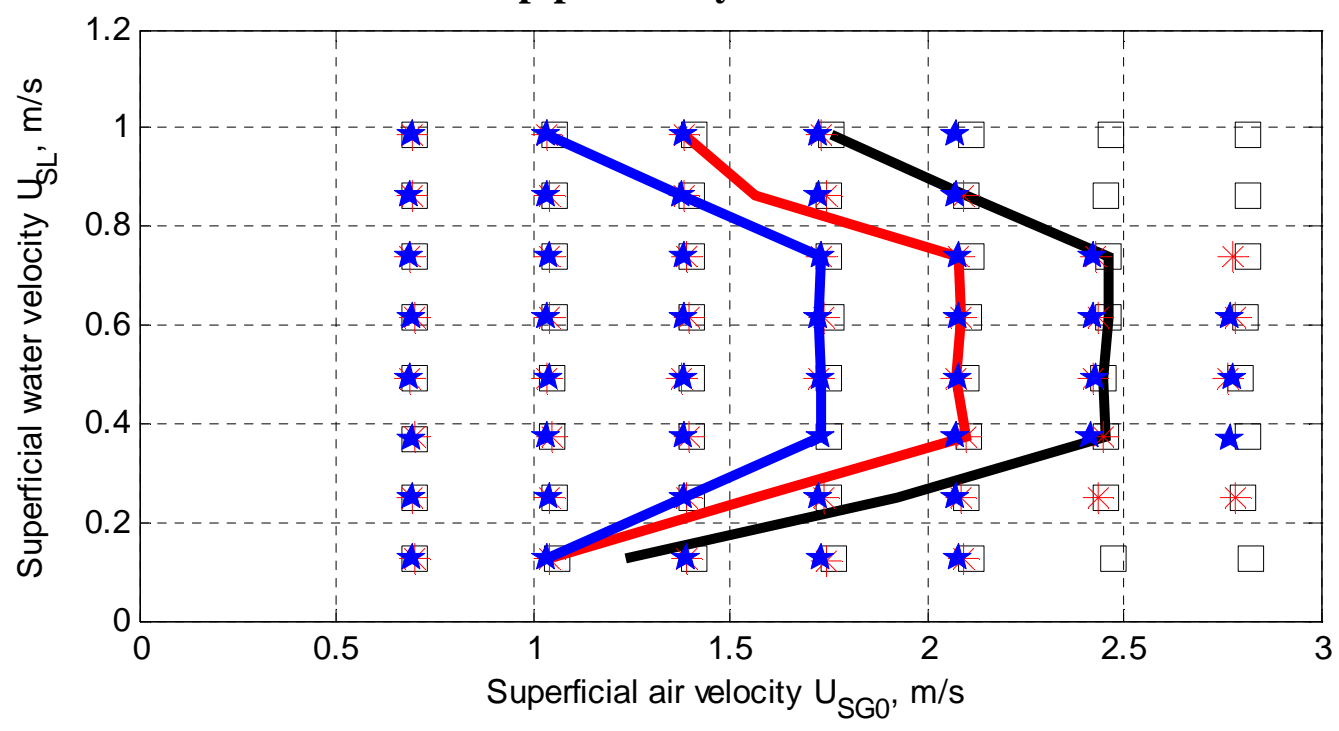

(a) Wavy pipe of 7 bends 


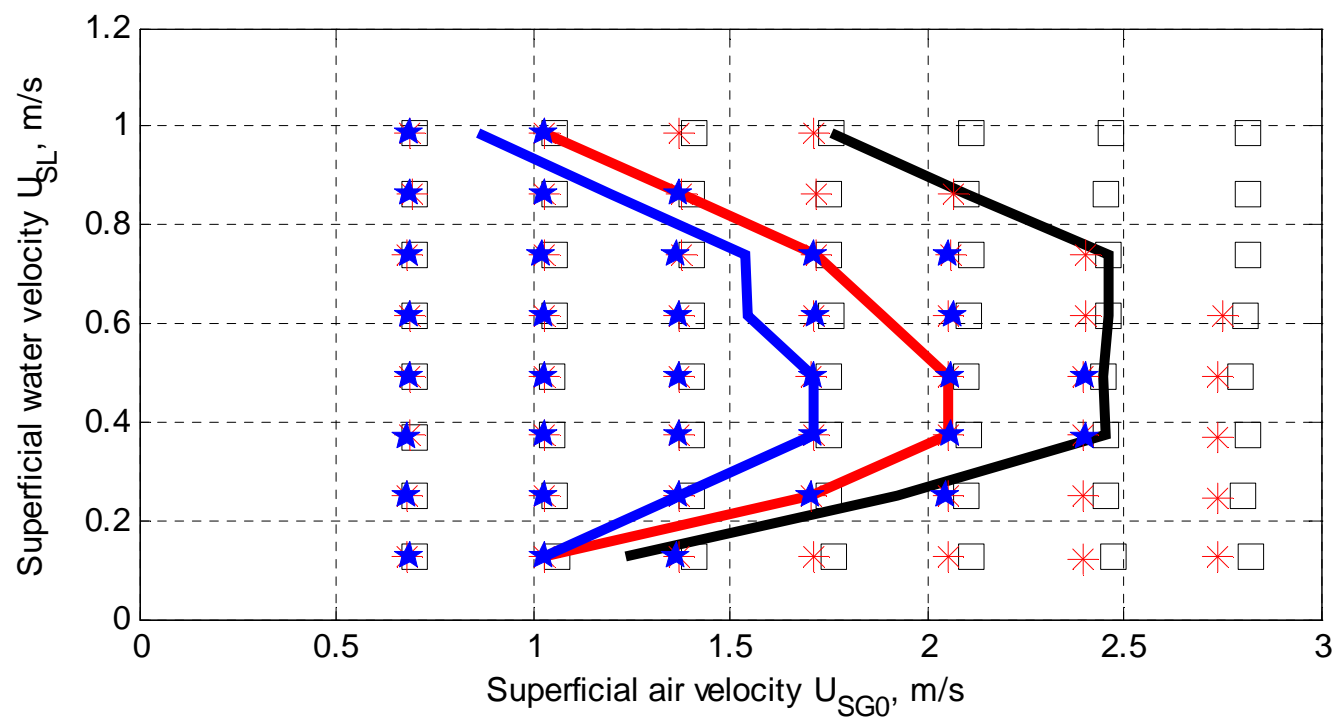

(b) Wavy pipe of 11 bends

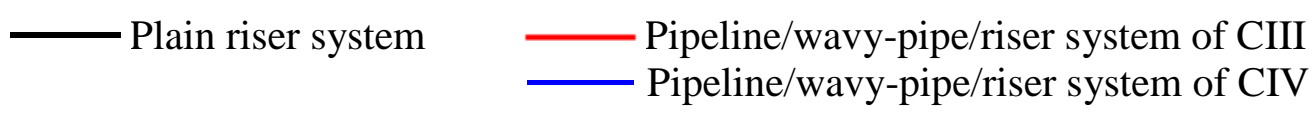

Fig. 7 Stability boundaries for the 2" plain riser and pipeline/wavy-pipe/riser systems with wavy pipes of 7 and 11 bends at different locations

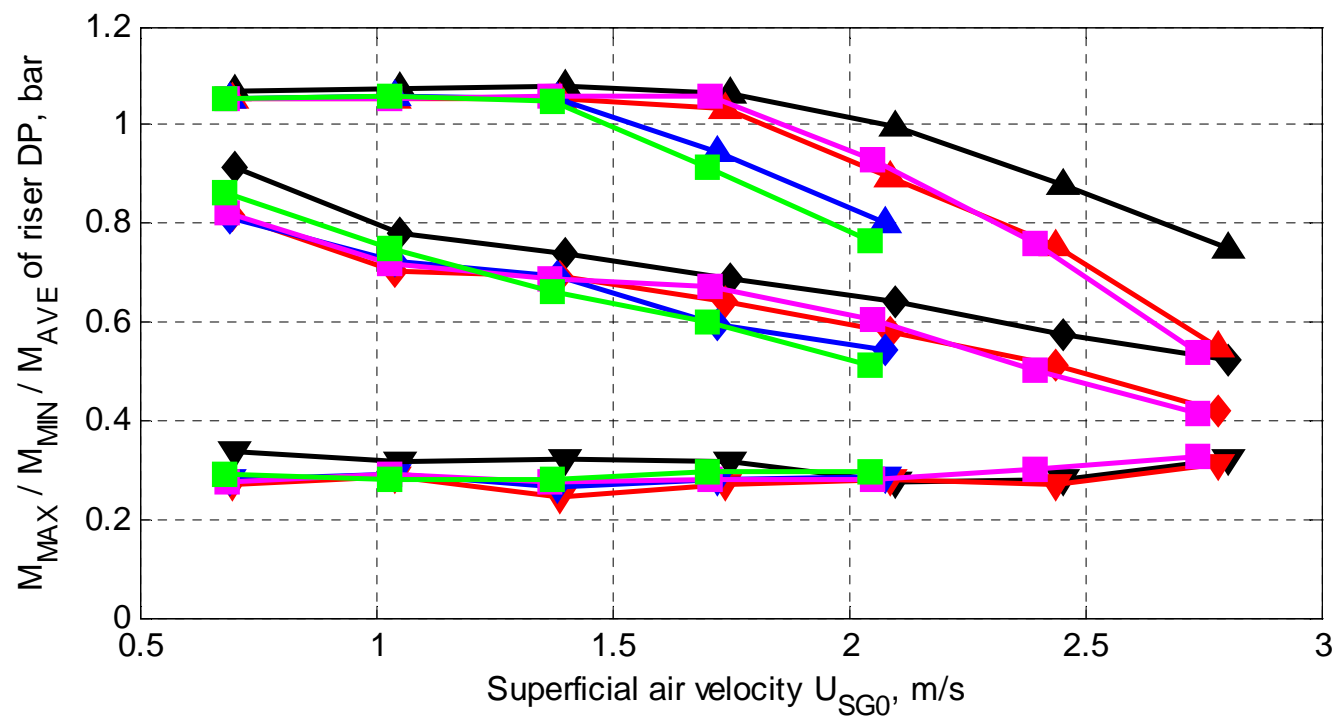

(a) $U_{\mathrm{SL}}=0.25 \mathrm{~m} / \mathrm{s}$ 


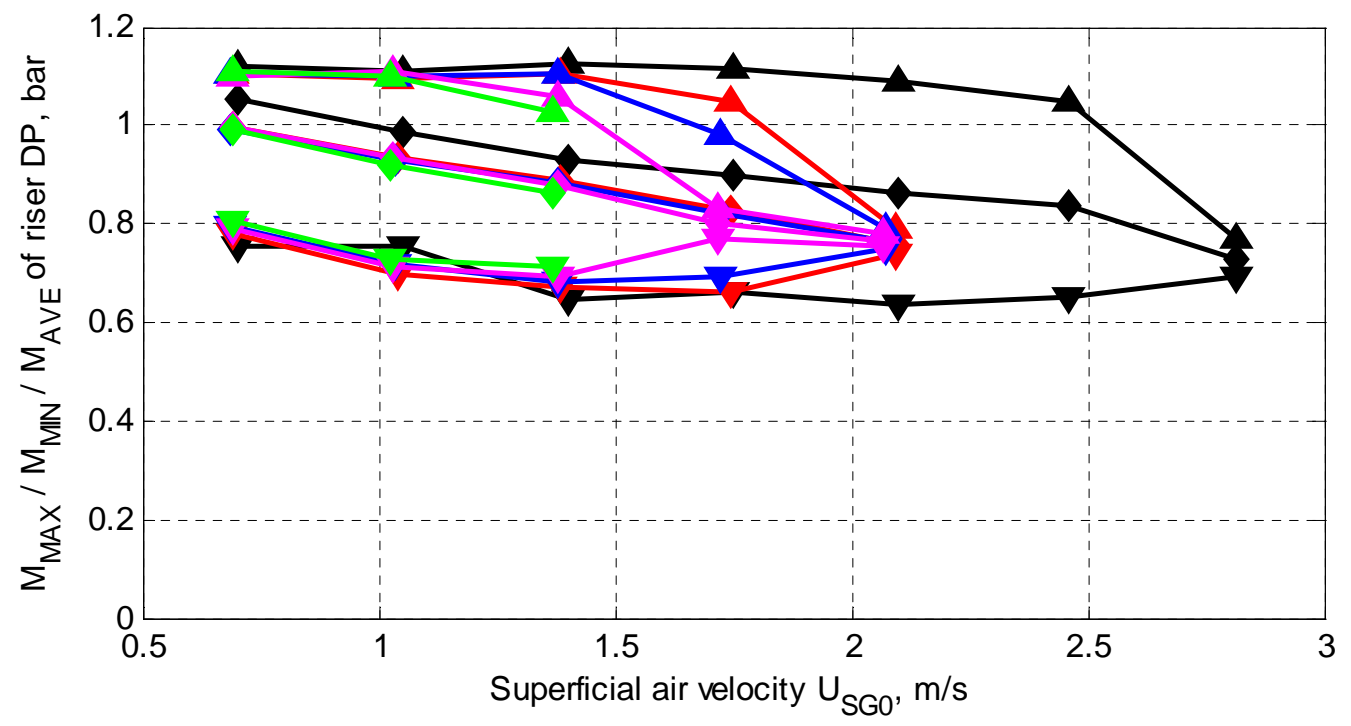

(b) $U_{\mathrm{SL}}=0.86 \mathrm{~m} / \mathrm{s}$

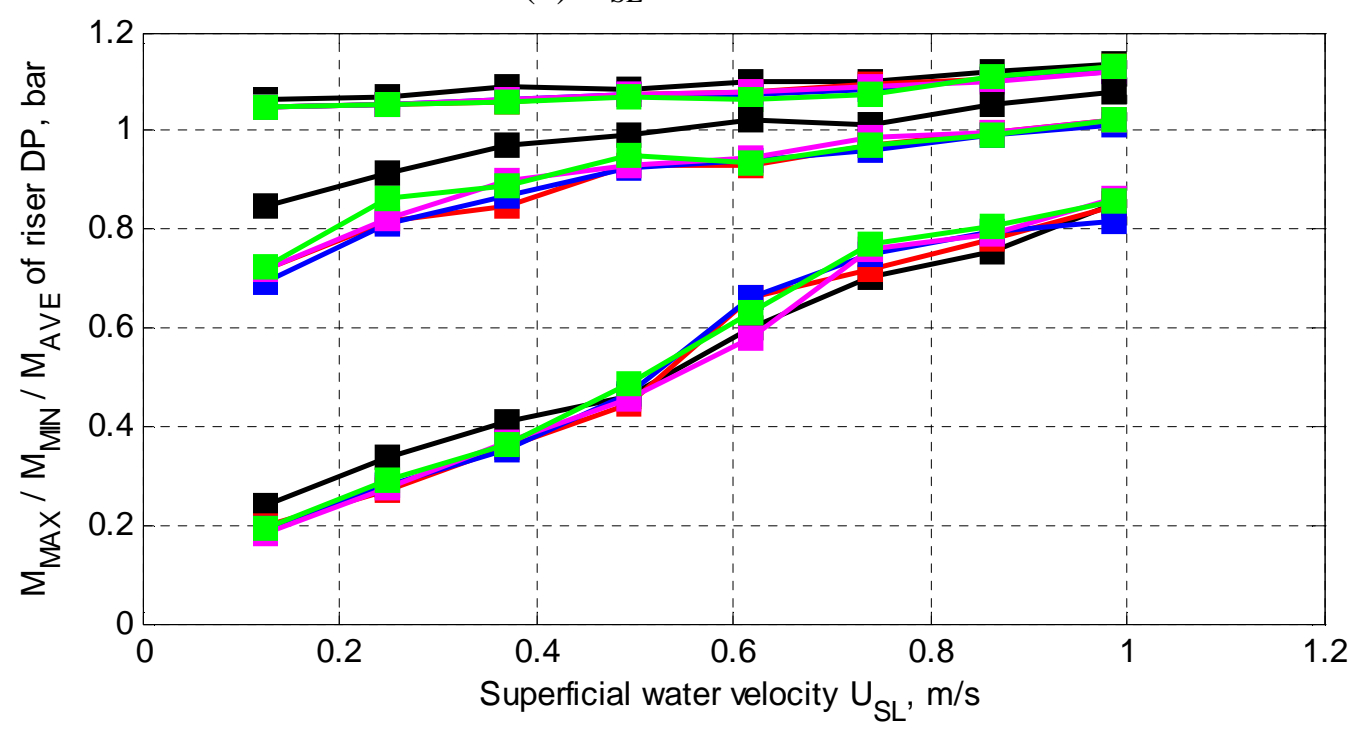

(c) $U_{\mathrm{SG} 0}=0.70 \mathrm{~m} / \mathrm{s}$

Plain riser system

7-bend wavy pipe of CI

11-bend wavy pipe of CIII 7-bend wavy pipe of CII

11-bend wavy pipe of CIV

Fig. $8 M_{\mathrm{MAX}}, M_{\mathrm{MIN}}$ and $M_{\mathrm{AVE}}$ of the riser DP for the 2" plain riser and pipeline/wavy-pipe/riser systems of different test configurations 


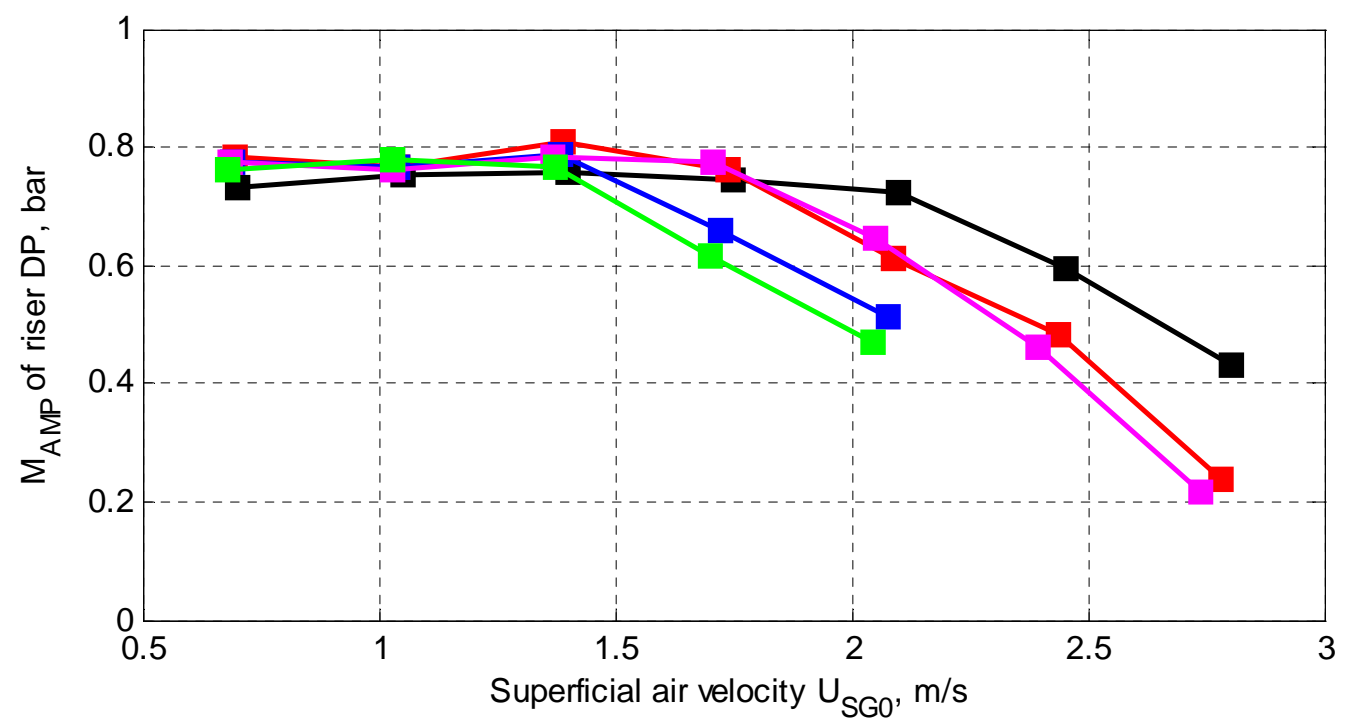

(a) $U_{\mathrm{SL}}=0.25 \mathrm{~m} / \mathrm{s}$

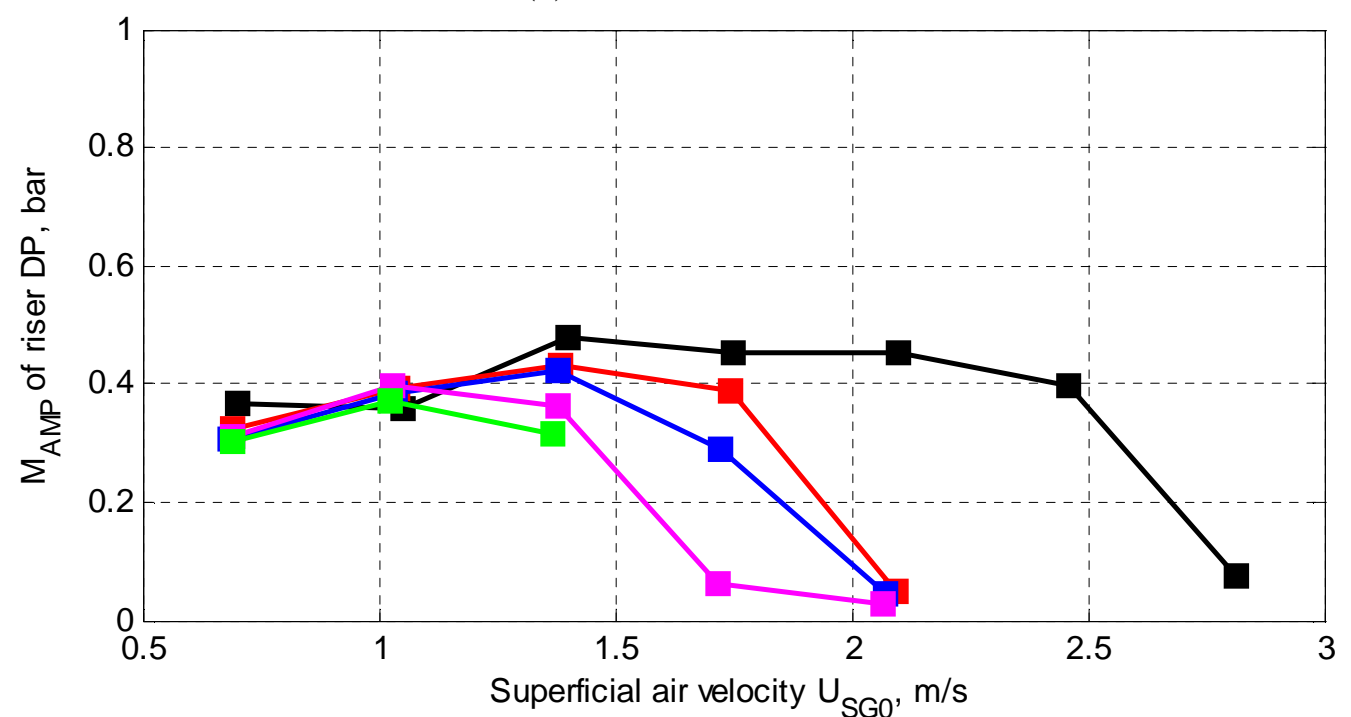

(b) $U_{\mathrm{SL}}=0.86 \mathrm{~m} / \mathrm{s}$

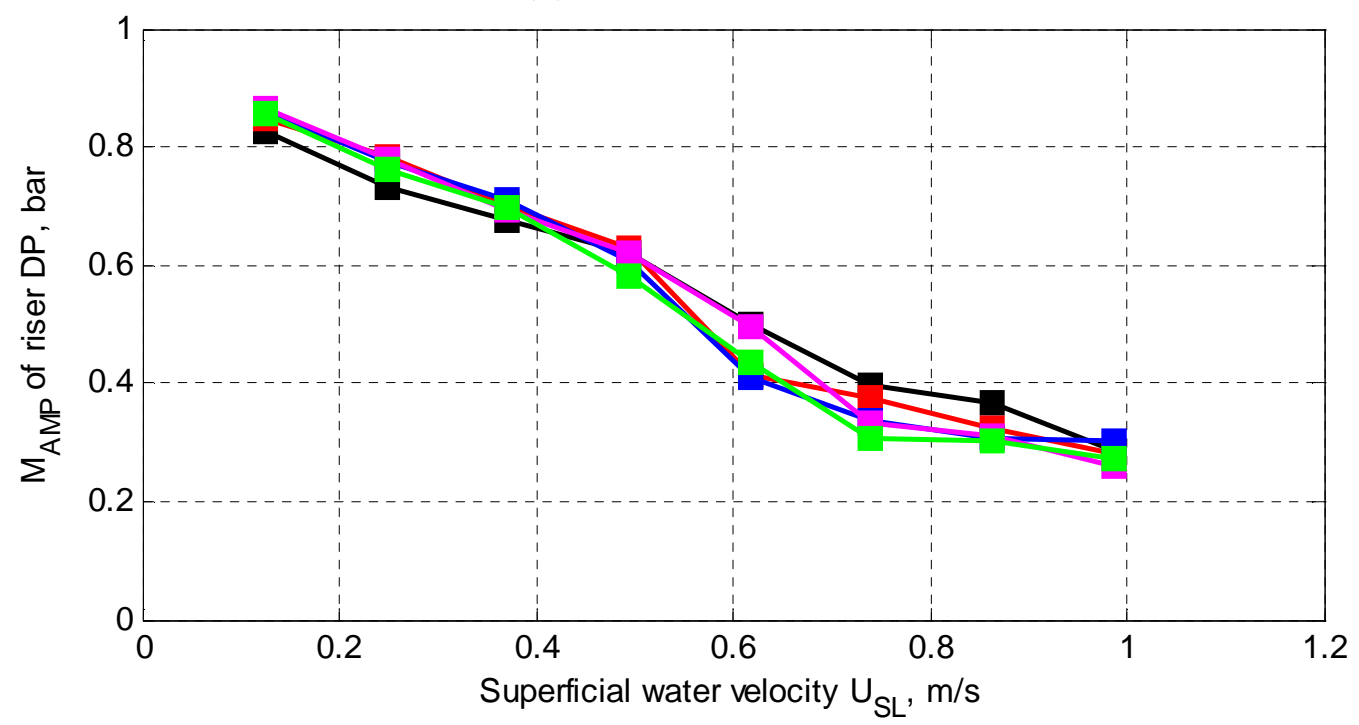

(c) $U_{\mathrm{SG} 0}=0.70 \mathrm{~m} / \mathrm{s}$

— Plain riser system 
Fig. $9 M_{\text {AMP }}$ of the riser DP for the 2" plain riser and pipeline/wavy-pipe/riser systems of different test configurations
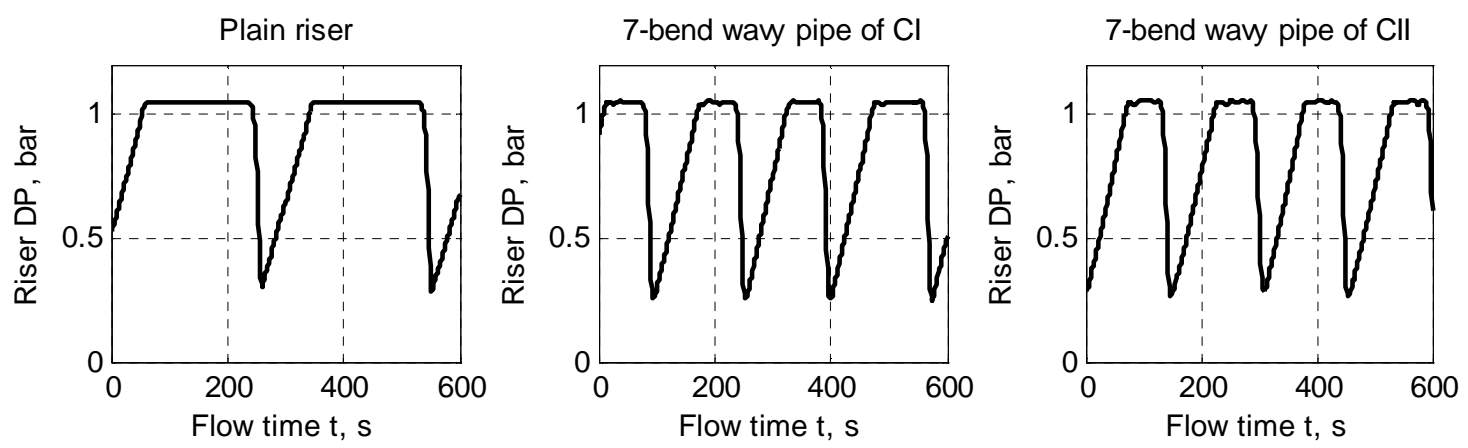

11-bend wavy pipe of CIII

11-bend wavy pipe of CIV
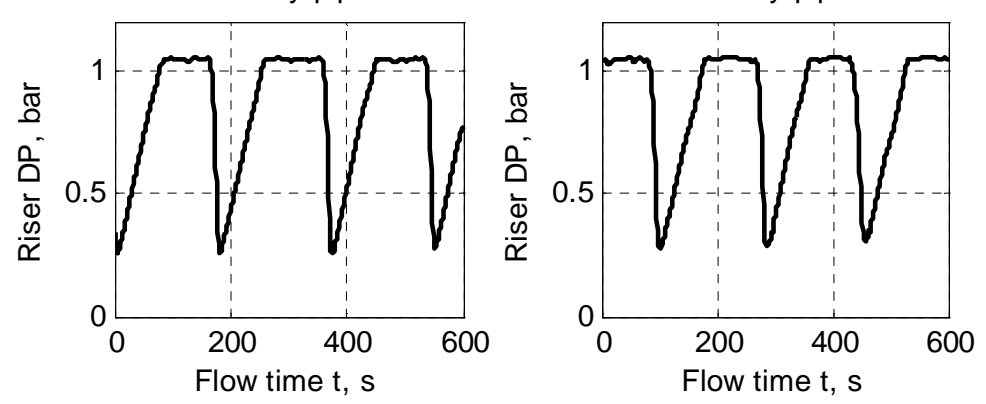

Fig. 10 Riser DP time traces of SS for the 2" plain riser and pipeline/wavypipe/riser systems of different test configurations $\left(U_{\mathrm{SG} 0}=0.70 \mathrm{~m} / \mathrm{s}, U_{\mathrm{SL}}=0.25\right.$ $\mathbf{m} / \mathbf{s})$

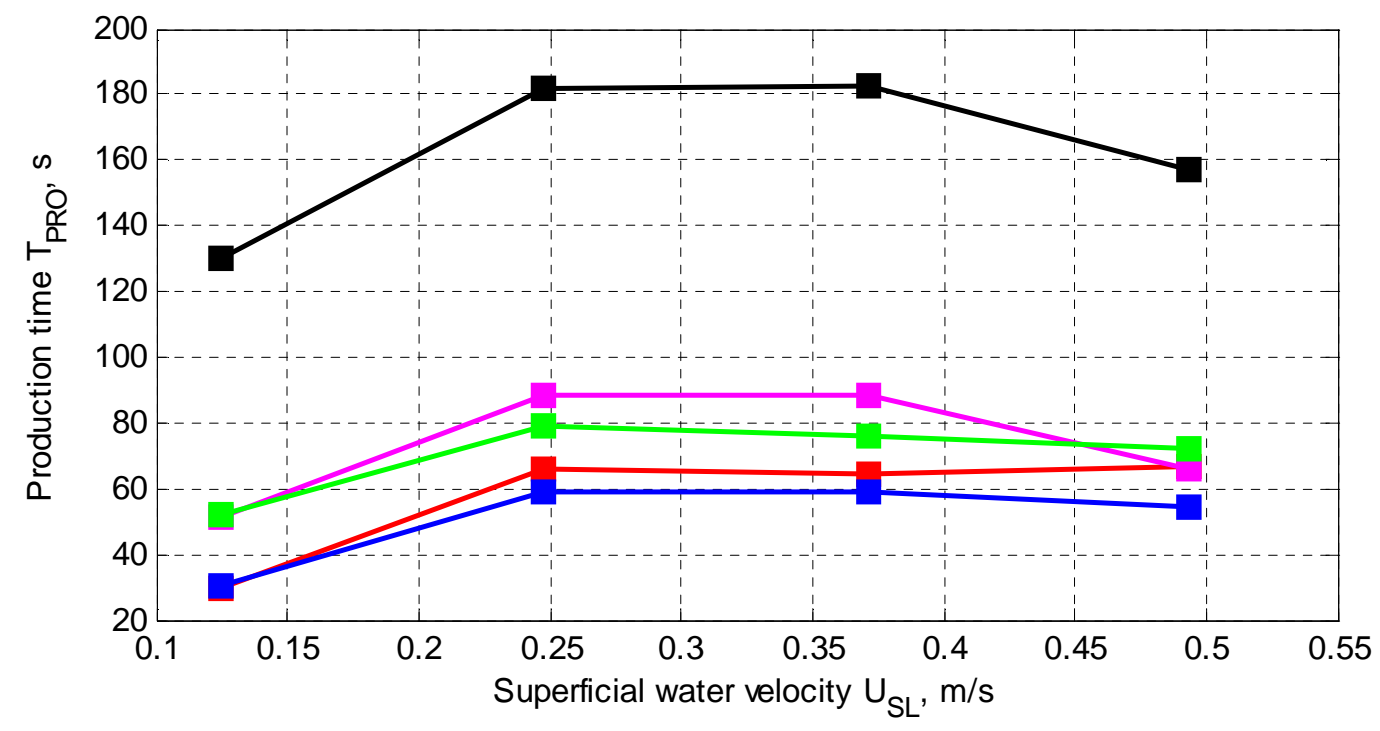

— Plain riser system 
Fig. $11 T_{\text {PRO }}$ of the riser DP for the 2" plain riser and pipeline/wavy-pipe/riser systems of different test configurations $\left(U_{\mathrm{SG} 0}=0.70 \mathrm{~m} / \mathrm{s}\right)$

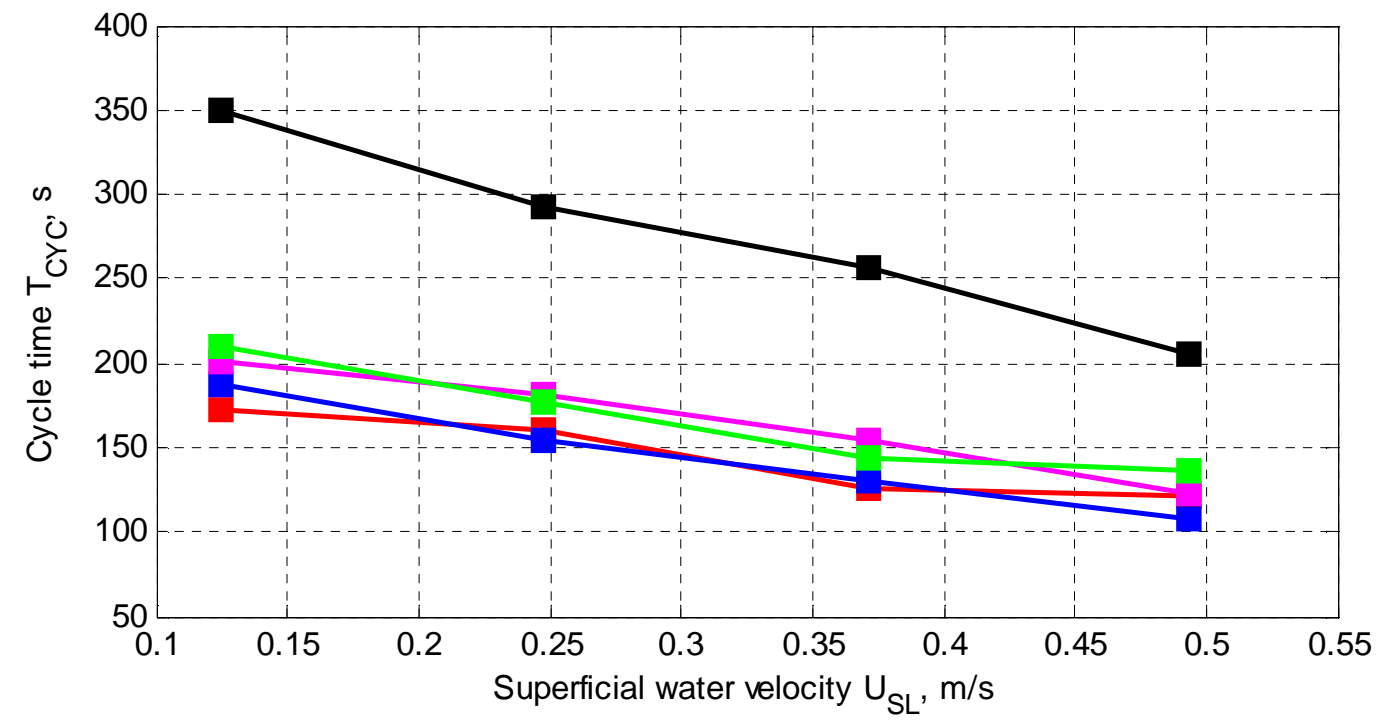

(a) $T_{\mathrm{CYC}}$

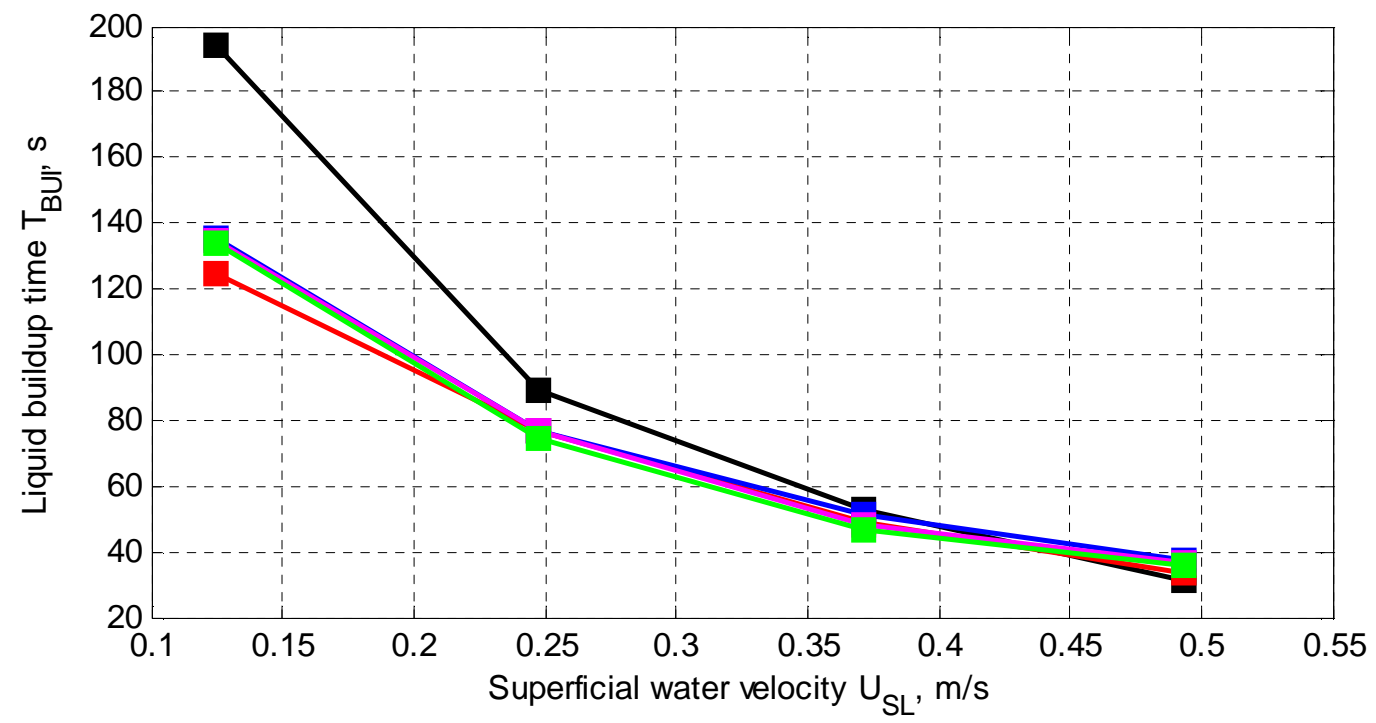

(b) $T_{\mathrm{BUI}}$ 


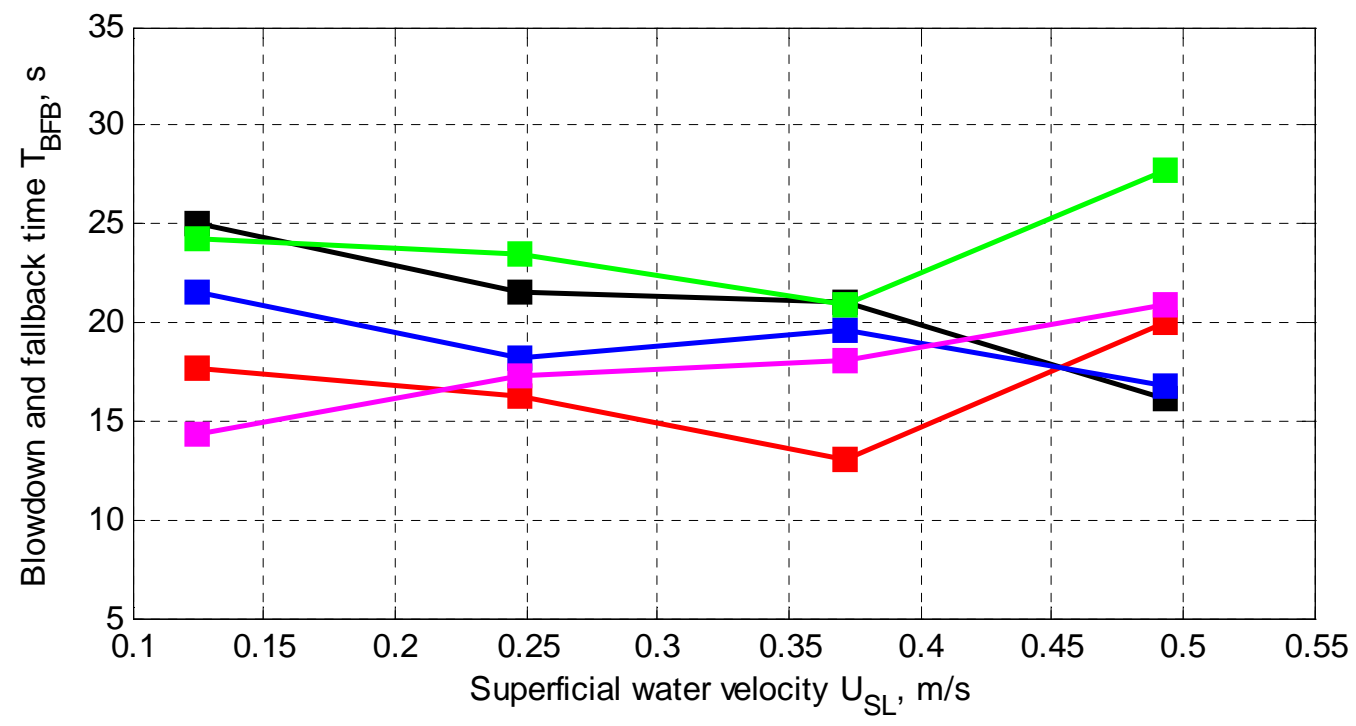

(c) $T_{\mathrm{BFB}}$

Plain riser system

Fig. $12 T_{\mathrm{CYC}}, T_{\mathrm{BUI}}$ and $T_{\mathrm{BFB}}$ of the riser DP for the 2" plain riser and pipeline/wavy-pipe/riser systems of different test configurations $\left(U_{\mathrm{SG} 0}=0.70 \mathrm{~m} / \mathrm{s}\right)$

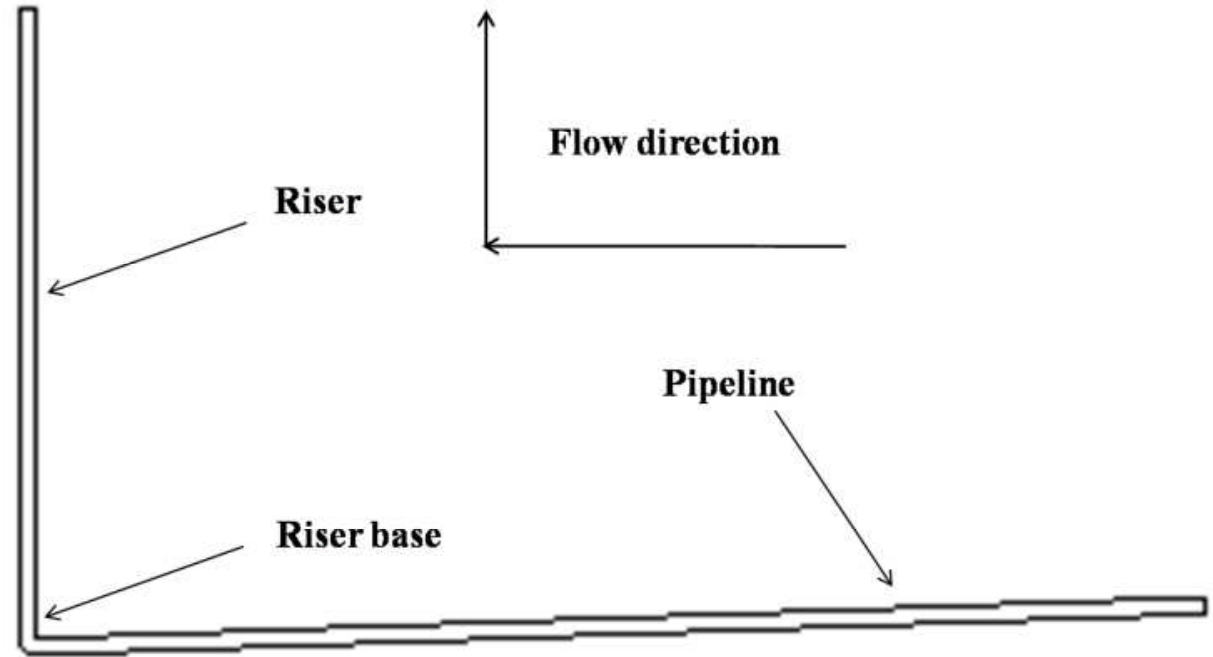

(a) Plain riser system 


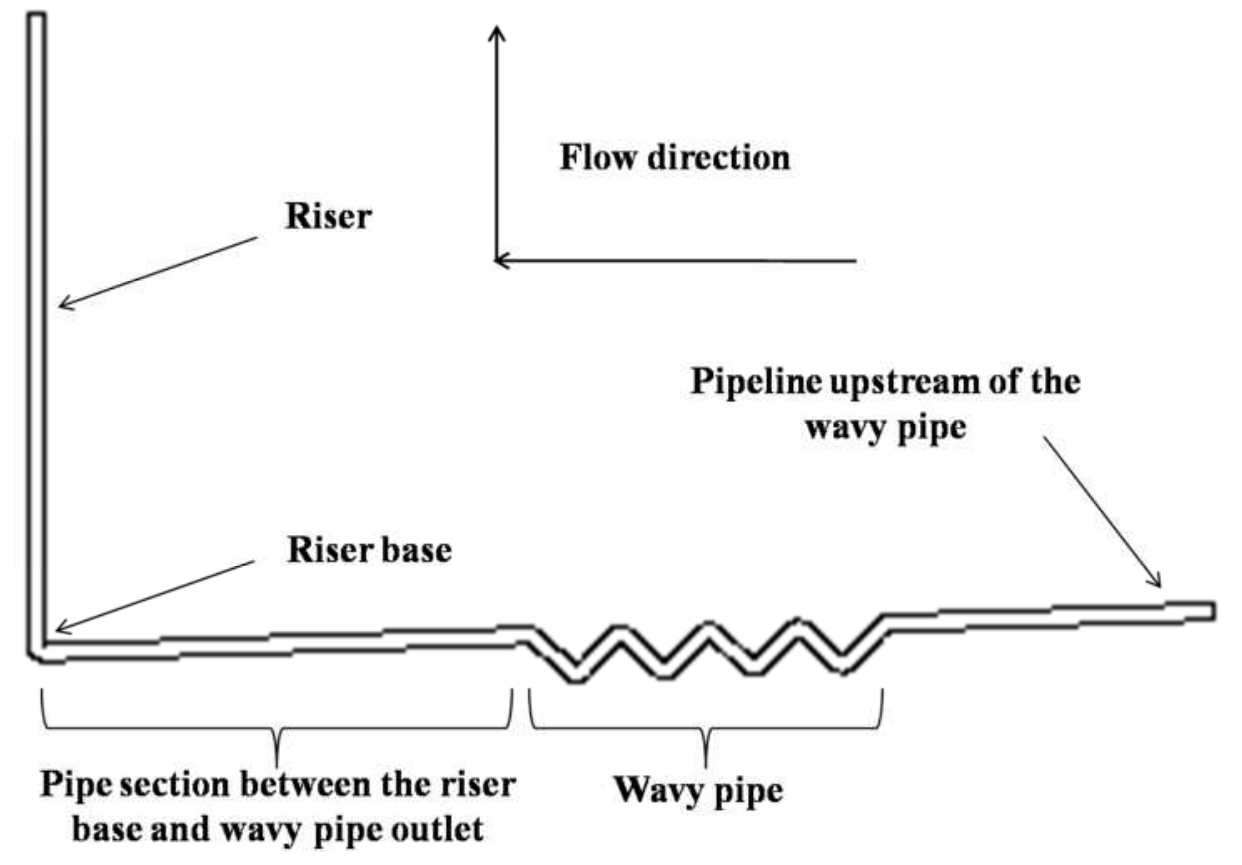

(b) Pipeline/wavy-pipe/riser system

Fig. 13 Schematics of the plain riser and pipeline/wavy-pipe/riser systems

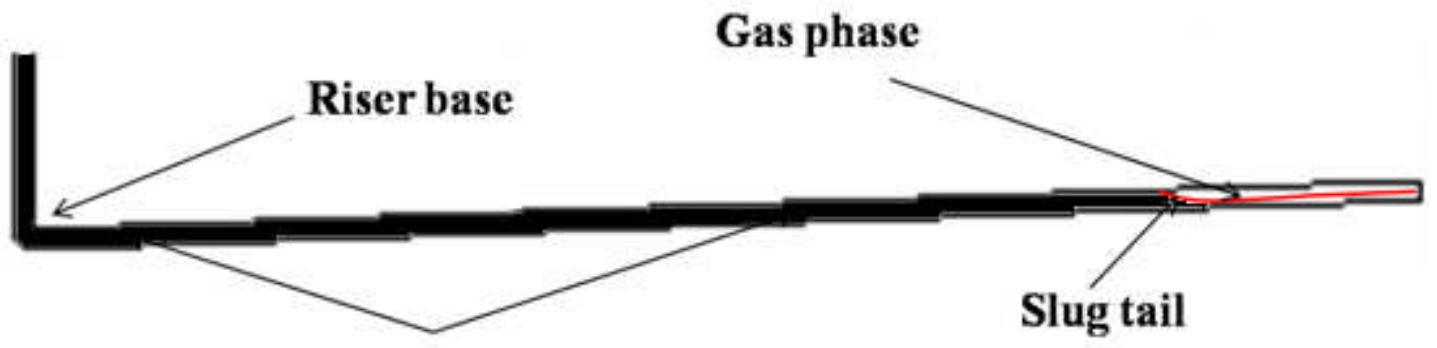

Liquid phase

(a) Plain riser system

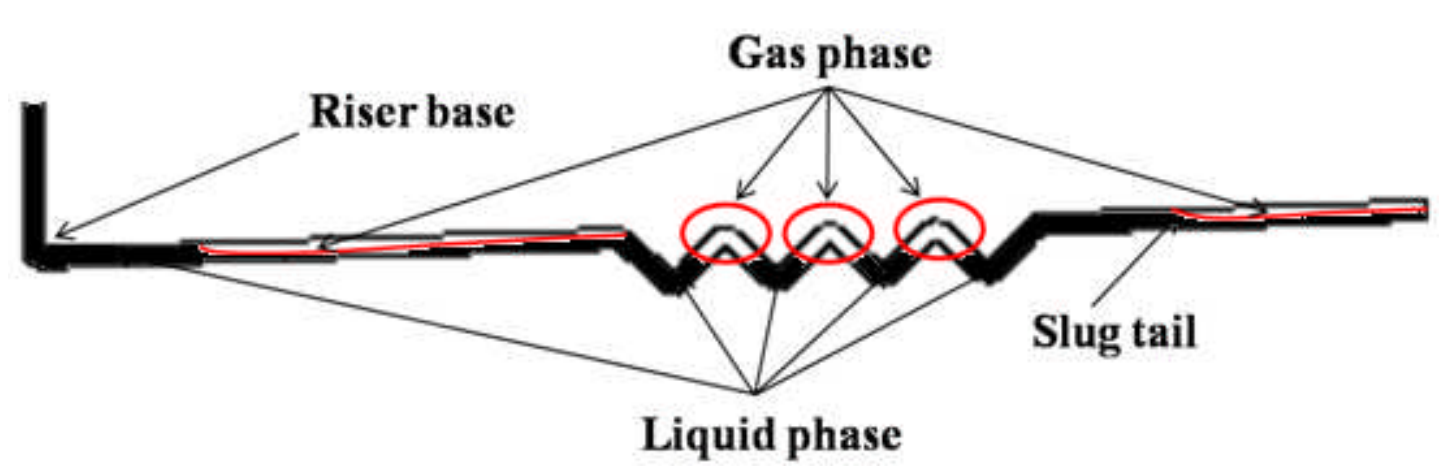

(b) Pipeline/wavy-pipe/riser system

Fig. 14 Schematics of the phase distribution upstream of the riser base in the plain riser and pipeline/wavy-pipe/riser systems 


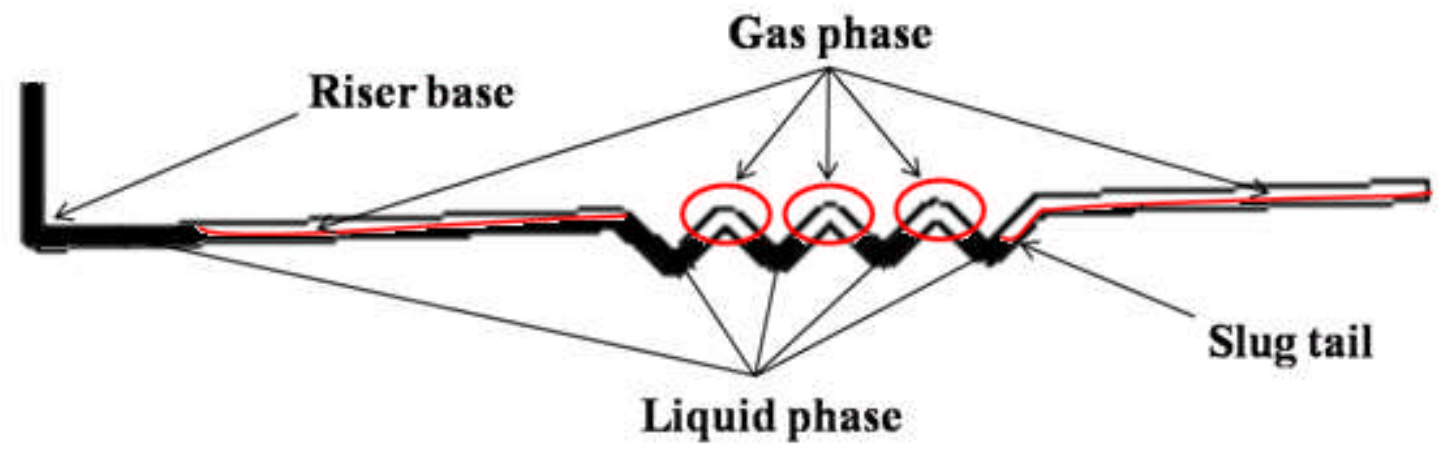

Fig. 15 Schematic of the phase distribution upstream of the riser base in the pipeline/wavy-pipe/riser system 